\title{
Comparative transcriptomic analysis of global gene expression mediated by ( $p)$ ppGpp reveals common regulatory networks in Pseudomonas syringae
}

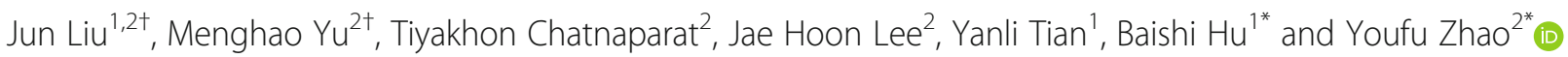

\begin{abstract}
Background: Pseudomonas syringae is an important plant pathogen, which could adapt many different environmental conditions. Under the nutrient-limited and other stress conditions, P. syringae produces nucleotide signal molecules, i.e., guanosine tetra/pentaphosphate ((p)ppGpp), to globally regulate gene expression. Previous studies showed that ( $p$ ) ppGpp played an important role in regulating virulence factors in $P$. syringae pv. tomato DC3000 (PstDC3000) and $P$. syringae pv. syringae B728a (PssB728a). Here we present a comparative transcriptomic analysis to uncover the overall effects of (p)ppGpp-mediated stringent response in P. syringae.

Results: In this study, we investigated global gene expression profiles of PstDC3000 and PssB728a and their corresponding (p)ppGpp mutants in hrp-inducing minimal medium (HMM) using RNA-seq. A total of 1886 and 1562 differentially expressed genes (DEGs) were uncovered between the (p)ppGpp ${ }^{0}$ mutants and the wild-type in PstDC3000 and PssB728a, respectively. Comparative transcriptomics identified 1613 common DEGs, as well as 444 and 293 unique DEGs in PstDC3000 and PssB728a, respectively. Functional cluster analysis revealed that (p) ppGpp positively regulated a variety of virulence-associated genes, including type III secretion system (T3SS), type VI secretion system (T6SS), cell motility, cell division, and alginate biosynthesis, while negatively regulated multiple basic physiological processes, including DNA replication, RNA processes, nucleotide biosynthesis, fatty acid metabolism, ribosome protein biosynthesis, and amino acid metabolism in both PstDC3000 and PssB728a. Furthermore, (p) ppGpp had divergent effects on other processes in PstDC3000 and PssB728a, including phytotoxin, nitrogen regulation and general secretion pathway (GSP).

\footnotetext{
*Correspondence: hbs@njau.edu.cn; zhao888@illinois.edu

†Jun Liu and Menghao Yu contributed equally to this work.

'College of Plant Protection, Key Laboratory of Integrated Management of Crop Diseases and Pests, Nanjing Agricultural University, Nanjing 210095,

P. R. China

${ }^{2}$ Department of Crop Sciences, University of Illinois at Urbana-Champaign,

1201 W. Gregory Dr., Urbana, IL 61801, USA
}

(c) The Author(s). 2020 Open Access This article is licensed under a Creative Commons Attribution 4.0 International License, which permits use, sharing, adaptation, distribution and reproduction in any medium or format, as long as you give appropriate credit to the original author(s) and the source, provide a link to the Creative Commons licence, and indicate if changes were made. The images or other third party material in this article are included in the article's Creative Commons licence, unless indicated otherwise in a credit line to the material. If material is not included in the article's Creative Commons licence and your intended use is not permitted by statutory regulation or exceeds the permitted use, you will need to obtain permission directly from the copyright holder. To view a copy of this licence, visit http://creativecommons.org/licenses/by/4.0/ The Creative Commons Public Domain Dedication waiver (http://creativecommons.org/publicdomain/zero/1.0/) applies to the data made available in this article, unless otherwise stated in a credit line to the data. 


\begin{abstract}
(Continued from previous page)
Conclusion: In this study, comparative transcriptomic analysis reveals common regulatory networks in both PstDC3000 and PssB728a mediated by (p) ppGpp in HMM. In both P. syringae systems, (p) ppGpp re-allocate cellular resources by suppressing multiple basic physiological activities and enhancing virulence gene expression, suggesting a balance between growth, survival and virulence. Our research is important in that due to similar global gene expression mediated by (p) ppGpp in both PstDC3000 and PssB728a, it is reasonable to propose that (p) ppGpp could be used as a target to develop novel control measures to fight against important plant bacterial diseases.
\end{abstract}

Keywords: RNA-seq, Secondary messenger, Stringent response, Virulence factors, DC3000, B728a

\section{Background}

Pseudomonas syringae is a widely-distributed gram negative plant pathogenic bacterium, which can adapt many different environmental conditions, and cause diseases on many different host plants, including bean, cabbage, cucumber, tomato, tobacco and rice $[1,2]$. P. syringae can be classified into more than 50 pathovars (pv) based on host specificities or symptoms [3]. Among them, $P$. syringae pv. tomato (Pst) causes bacterial speck disease of tomato [4], and has served as a model system in plant-microbe interactions [5]. Whereas $P$. syringae pv. syringae (Pss) is the causal agent of brown spot on bean and an excellent epiphyte, which serves as a model system to study epiphytic fitness of pathogens on plant surfaces $[6,7]$. P. syringae utilizes many virulence factors, including phytotoxins, exopolysaccharide [8], and the type III secretion system (T3SS) $[9,10]$. The T3SS in $P$. syringae is transcriptionally regulated by a RNA polymerase sigma factor $\mathrm{HrpL}$, which is activated by an alternative sigma factor RpoN, along with bacterial enhancer-binding proteins HrpS and HrpR $[11,12]$. The T3SS genes are rapidly induced under limited nutrition (minimal medium), low $\mathrm{pH}$ and relatively low temperature; and are induced in planta or by iron, but inhibited in rich medium [13, 14].

Nucleotide second messengers are the major signal transduction molecules of bacteria, including c-di-GMP, c-di-AMP, cGMP, cAMP and (p) ppGpp [15]. These nucleotides control diverse cellular processes in response to environmental stresses for survival and virulence [15]. The guanosine tetraphosphate (ppGpp) and pentaphosphate (pppGpp), thereafter referred to as (p) ppGpp, are first discovered as bacterial 'alarmone' compounds produced under nutrient starvation [16]. When bacteria are under fatty acid, amino acid, phosphate, carbon or iron starvation, the RelA-SpoT homologue (RSH) proteins are activated to produce (p) ppGpp [16, 17], where bacteria re-allocate cellular resources by inhibiting DNA synthesis, RNA stability, ribosomal protein synthesis and membrane modules, and at the same time, by promoting key factors for stress resistance, glycolysis and amino acid biosynthesis. This process is referred to as the "stringent response" [16].
When amino acids are limited, uncharged tRNAs bind to the ribosomal A-site to activate the ribosomeassociated protein RelA, which synthesizes (p) ppGpp [18]. In contrast, SpoT is a bifunctional enzyme that synthesizes and degrades (p)ppGpp. SpoT synthesizes (p) ppGpp in response to a lack of fatty acids, carbon, phosphorus, or iron, as well as hyperosmotic shock and oxidative stress [19, 20]. In Escherichia coli, (p) ppGpp regulates target genes through two mechanisms [21, 22]. On one hand, (p) ppGpp directly binds to the active sites of RNA polymerase (RNAP) to inhibit transcription involved in cell growth, cell division and to activate amino acid biosynthesis [2325]. On the other hand, (p) ppGpp indirectly reduces the affinity of core RNAP and $\sigma^{70}$, which leads to an increased availability of free RNAP. Alternative sigma factors in turn bind to RNAP to activate stress response genes, including oxidative and osmotic stress genes [16, 24].

Previous studies have shown that (p) ppGpp plays a central role in many processes related to survival and virulence $[16,17]$. The (p)ppGpp ${ }^{0}$ mutants of PstDC3000 and PssB728a were both non-pathogenic and their growth in planta was significantly reduced $[26,27]$. Furthermore, (p) ppGpp deficiency led to decreased expression of T3SS, loss of swarming motility, reduction of pyoverdine production, increased sensitivity to oxidative stress and antibiotic tolerance, as well as reduced ability to utilize $\gamma$-amino butyric acid $[26,27]$. Moreover, cell sizes of the (p)ppGpp ${ }^{0}$ mutants were increased and their survival on plant surfaces was significantly decreased at $24 \mathrm{~h}$ after inoculation [26, 27], indicating that (p) ppGpp plays a major role in regulating gene expression for growth, survival and virulence. In this study, we performed a global transcriptomic analysis to compare gene expression between PstDC3000 and its relA/spoT/fpRel triple mutant ((p)ppGpp $\left.{ }^{0}{ }_{P s t \mathrm{DC} 3000}\right)$, and between PssB728a and its relA/ spoT double mutant ((p)ppGpp $\left.{ }_{P s s B 728 \mathrm{a}}^{0}\right)$. The purpose was to determine the global effects of (p) ppGpp and to compare the two $P$. syringae systems to illustrate their similarities or differences in the global effects of the (p)ppGpp-mediated stringent response. 


\section{Results and discussion}

Overview of gene expression profiles and transcriptomic analysis

In previous studies, we reported that (p) ppGpp production in PssB728a depended on two enzymes, i.e., RelA and SpoT; whereas its production in PstDC3000 relied on three enzymes, i.e., RelA, SpoT and fpRel [26, 27]. We also demonstrated that the stringent response mediated by $(\mathrm{p})$ ppGpp plays a major role in virulence and survival in both PstDC3000 and PssB728a [26, 27]. In order to further understand its global effect, RNA-seq comparing the wildtype and the (p)ppGpp ${ }^{0}$ mutant was conducted in both $P$. syringae systems. In total, $11,261,275$ to $23,836,829$ reads for each biological sample were generated for PstDC3000 and its triple mutant ((p)ppGpp $\left.{ }_{P s t \mathrm{DC} 3000}\right)$, and the percentage of reads mapped to PstDC3000 genome ranged from 96.4 to $97.5 \%$; whereas $13,562,836$ to $22,961,086$ reads for each biological sample were obtained for PssB728a and its double mutants ((p)ppGpp $\left.{ }_{\text {PssB728a }}^{0}\right)$, and the percentage of reads mapped to PssB728a genome were from 96.8 to $97.3 \%$.

To explore the similarities and differences between these samples, principal component analysis (PCA) was conducted within the two $P$. syringae systems. PCA plot clearly showed that the first two components (PC1 and PC2) explained about 91 and $87 \%$ of the variability in the datasets for PstDC3000 and PssB728a and their corresponding mutant strains, respectively (Fig. 1a \& b). In both cases, the three biological samples of each strain clustered together, suggesting that variation mainly came from the difference between the wild-type and the (p)ppGpp ${ }^{0} \mathrm{mu}$ tant. Heatmap also showed that the three biological samples were very consistent (Additional file 1: Figure S1).

A total of 1886 and 1562 differentially expressed genes (DEGs), which displayed a $\left|\log _{2} \mathrm{FC}\right|$ value $\geq 1$ and a corrected $p$ value $<0.05$ between PstDC3000 and PssB728a and its corresponding (p)ppGpp ${ }^{0}$ mutant, were respectively identified. (Additional file 1: Figure S1), representing
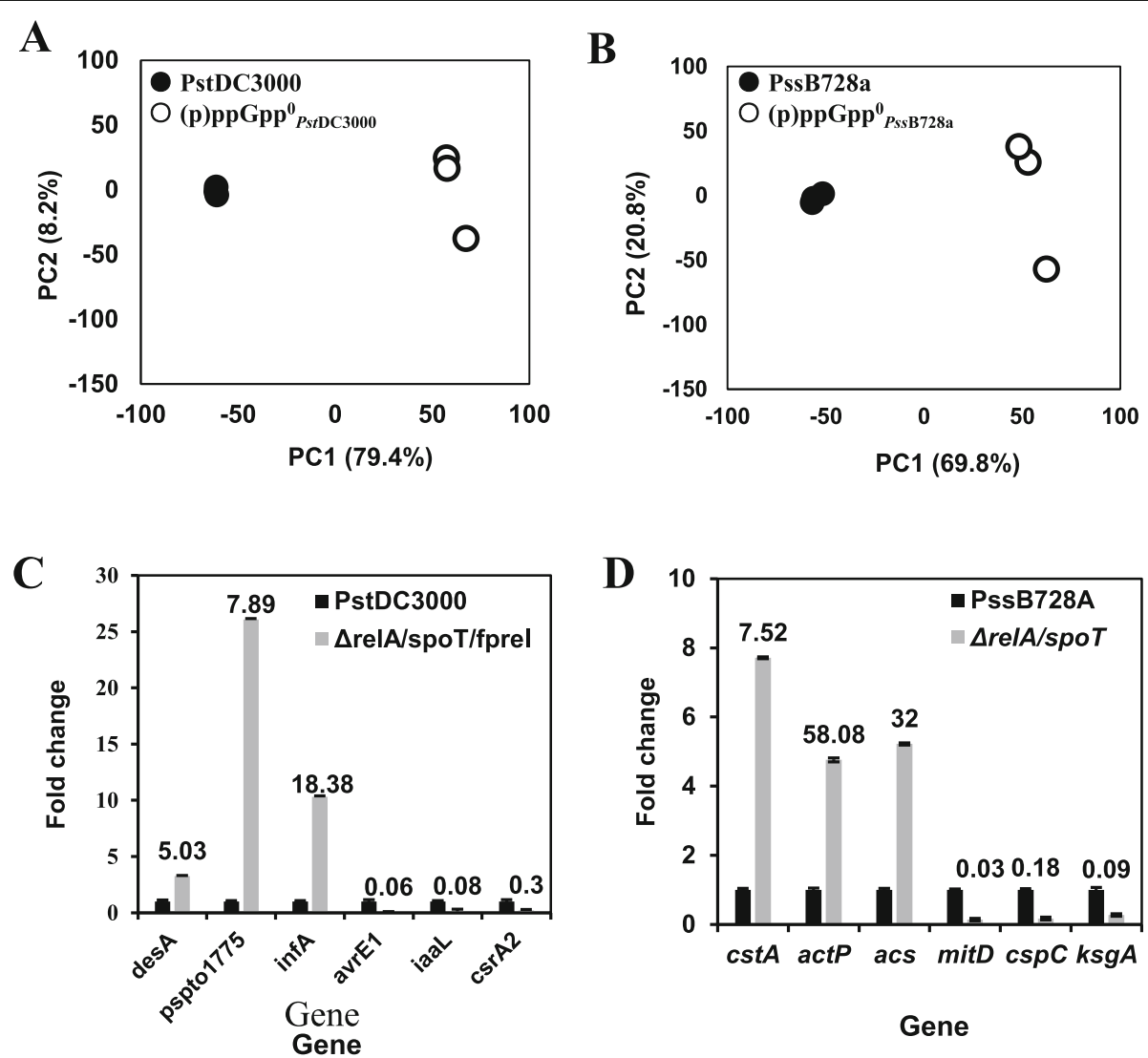

Fig. 1 Principal component analysis (PCA) and verification of differential expressed genes (DEGs) by Quantitative real-time PCR. a PC1 and PC2 explain data variability of 79.4 and $8.2 \%$, respectively, for PstDC3000 and its (p)ppGpp 0 mutant. b PC1 and PC2 explain data variability of 69.8 and 20.8\%, respectively, for PssB728a and its (p)ppGpp ${ }^{0}$ mutant. c Expression of the desA, pspto_1775, infA, avrE1, iaaL and csrA2 genes in the relA/ spoT/fpRel ((p)ppGpp ${ }^{0}$ ) mutant strain as compared with PstDC3000 grown in hrp-inducing medium at $3 \mathrm{~h}$ post-inoculation. $\mathbf{d}$ Expression of the $\operatorname{cst} A, \operatorname{act} P, a c s A, m t i D, c s p C$ and ksgA genes in the relA/spoT ((p)ppGpp $\left.{ }^{0}\right)$ mutant strain as compared with PssB728a grown in hrp-inducing medium at $3 \mathrm{~h}$ post-inoculation. Numbers on the bar indicate fold change by RNA-seq 
about one third of genes in both $P$. syringae genomes. Among them, 945 genes were up-regulated and 941 genes

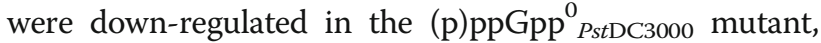
whereas 701 genes were up-regulated and 861 genes were down-regulated in the (p)ppGpp ${ }_{\text {PssB728a }}^{0}$ mutant (Additional file 1: Figure S2). To verify the RNA-seq data, 12 genes were selected, including genes encoding indoleacetate-lysine ligase (IaaL), fatty acid desaturase (DesA), ATP-dependent RNA helicase, DEAD box family (Pspto_1775), carbon storage regulator (CsrA2), type III effector protein (AvrE1) and translation initiation factor IF-1 (InfA) from PstDC3000. Genes encoding mannitol dehydrogenase (MtiD), acetate permease (ActP), acetyl-CoA synthetase (AcsA), carbon starvation protein (CstA), cold-shock protein $(\mathrm{CspC})$ and dimethyladenosine transferase (KsgA) were selected for PssB728a. The qRT-PCR results showed that expression of selected genes was mostly in similar trend as those of the RNA-seq data (Fig. 1c \& d). In addition, expression of T3SS and toxin biosynthesis genes was previously verified [26, 27].

DEGs were then functionally categorized based on the clusters of orthologous groups (COGs) (Additional file 2: Table S1 \& S2). In total, 1202 DEGs for PstDC3000 and 1009 DEGs for PssB728a were functionally separated into 20 out of 21 known function categories (Fig. 2a \& b), supporting the notion that (p) ppGpp is a global regulator. In general, most of the DEGs categorized as T3SS, signal transduction, cell motility, and carbohydrate metabolism were positively regulated by (p)ppGpp. In contrast, most DEGs belonging to translation, transcription, replication/ recombination/repair, posttranslational modification, coenzyme metabolism, and nucleotide metabolism were negatively regulated by (p) ppGpp (Fig. 2a \& b).

\section{Comparative transcriptomic analysis reveals common regulatory networks in two pathovars of Pseudomonas syringae}

In order to determine the similarities and differences between effects of (p) ppGpp in PstDC3000 and PssB728a, a comparative transcriptomic analysis was performed. In the genomes of PstDC3000 and PssB728a, there are 5483 and 5137 protein-coding genes, respectively [6]. Among them, 4210 homologous genes with more than $40 \%$ sequence identity $\left(\mathrm{E}<10^{-2}\right)$ are shared (Fig. 3, outside ring 1, sky blue; Additional file 3: Table S3), representing about three fourths of the genomes. The remaining 1273 and 927 genes are unique for PstDC3000 and PssB728a, respectively (Fig. 3, outside ring 1, yellow and pink; Additional file 3: Table S3). When DEGs of the (p)ppGpp ${ }_{P_{s t} \mathrm{DC} C 3000}$ mutant versus PstDC3000 (Fig. 3, Ring 2) and the (p)ppGpp ${ }^{0}{ }_{\text {Pss B } 228 a}$ mutant versus PstB728a (Fig. 3, Ring 4) were mapped to the corresponding genes in the genome, similar expression patterns for homologous genes in PstDC3000 and PssB728a were observed. Interestingly, unique genes belonging to the same COGs in the two P. syringae systems were also shown similar expression profiles (Fig. 3, Ring 3). These results suggested that (p) ppGpp exhibited similar effects on global gene expression in both PstDC3000 and PssB728a in HMM. However, one caveat of this research was that we only determined gene expression at one time point.

A total of 1613 homologous genes were simultaneously differentially expressed (with adjusted $p$-values $<0.05$ and at least one $\left|\log _{2} \mathrm{FC}\right|$ value $\geq 1$ ) in comparison of the (p)ppGpp ${ }^{0}{ }_{P s t \mathrm{DC} 3000}$ mutant versus $P s t \mathrm{DC} 3000$ and the (p)ppGpp ${ }_{\text {PssB728a }}^{0}$ mutant versus $P s t \mathrm{~B} 728$ a (Additional file 3: Table S4). These genes were further functionally categorized based on COGs, thus reflecting the common global effects of (p) ppGpp in P. syringae (Fig. 4). Furthermore, transcriptomic analysis identified 255 homologues DEGs inversely regulated by (p) ppGpp (Additional file 3: Table S5). A total of 444 and 293 unique DEGs, which were regulated by (p) ppGpp in PstDC3000 and PssB728a, respectively, were also identified (Additional file 4: Table S6 \& S7).

\section{Positive regulation of virulence-associated genes in $P$. syringae \\ Type III and type VI secretion system (T3SS and T6SS)}

Bacteria rely on protein secretion systems to acquire essential nutrients and suppress or evade the host immune system during infection of the host plants [28]. Among the six different secretion systems [28-30], T3SS specifically secretes and translocates effector proteins from the bacteria to the cytoplasm of the host cell through the needle-like apparatus [31, 32]. T3SS is a key pathogenicity factor in both PstDC3000 and PssB728a and injects effector proteins into host cells to suppress host defense and cause disease $[7,33,34]$. In the regulatory networks of $P$. syringae, a sigma factor cascade (RpoN-HrpL) quickly activates T3SS under nutrient-limited conditions $[11,12,35]$. Previous studies have reported that accumulation of (p) ppGpp leads to increased transcription of genes regulated by alternative sigma factors, such as RpoN, which interacts with bacterial enhancer-binding proteins HrpS and HrpR [12, 35]. Chatnaparat et al. reported that the $h r p L, h r p R, h r p S$ and $h r p Z$ genes were significantly down-regulated in the (p)ppGpp ${ }^{0}{ }_{\text {sst } \mathrm{DC} 3000}$ and (p)ppGpp ${ }_{\text {PssB728a }}^{0}$ mutants, indicating that (p) ppGpp is required for activating T3SS in both PstDC3000 and PssB728a. In this study, 38 T3SS-related genes, including $h r p L, h r p-h r c$ gene clusters and many effector genes, were down-regulated by more than twofold in the (p)ppGpp ${ }_{\text {PstDC3000 }}^{0}$ and (p)ppGpp ${ }_{\text {PssB728a }}^{0}$ mutants (Fig. 5a; Additional file 5: Table S8).

T6SS is implicated in bacterial interaction, competition and fitness [30, 36, 37]. Putative T6SS clusters have been reported previously in P. syringae pathovars [30]. One of the three T6SSs in Pseudomonas aeruginosa and 

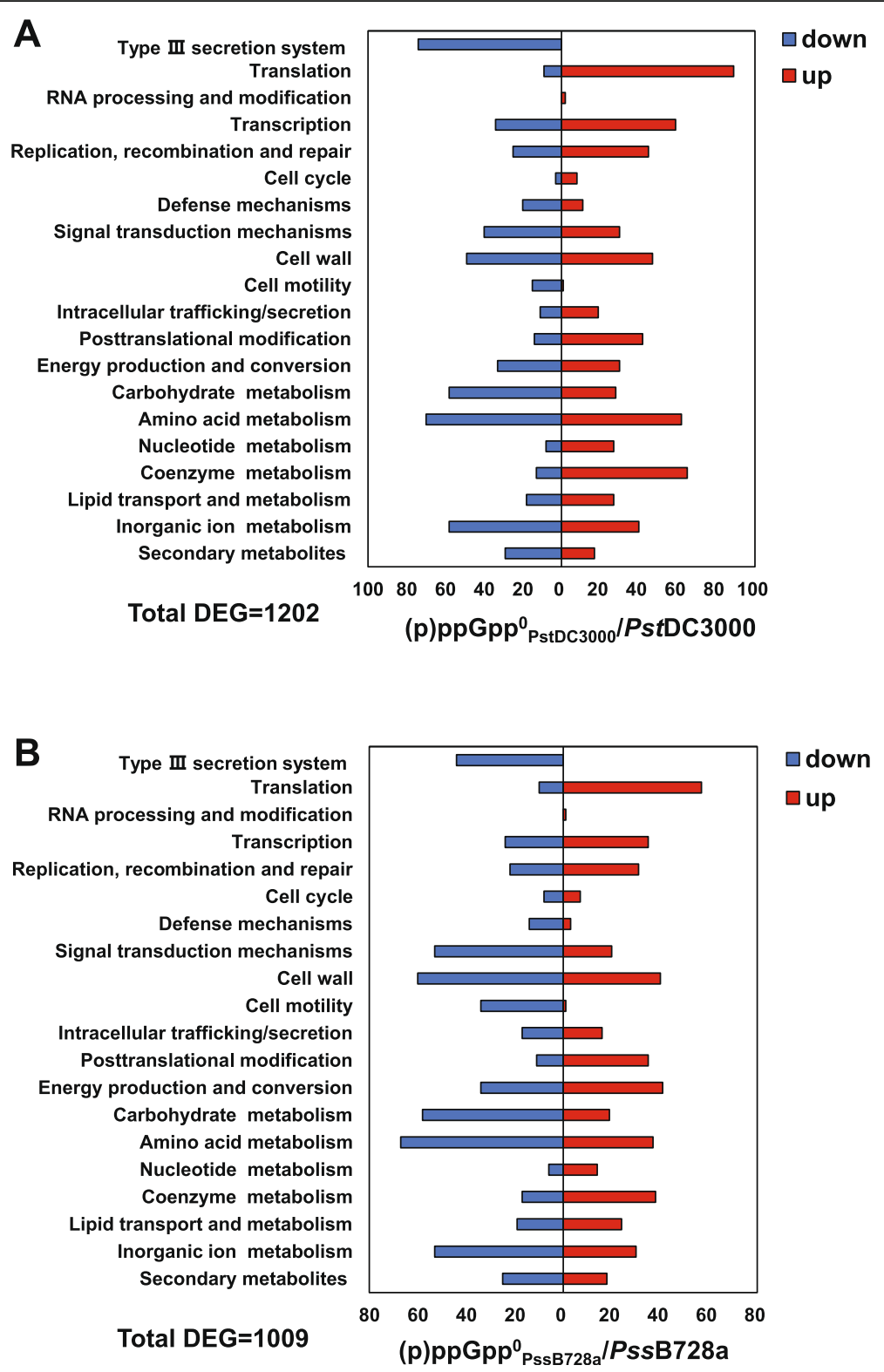

Fig. 2 Functional classification of differential expressed genes (DEGs) based on the clusters of orthologous groups (COGs). a PstDC3000 and (p)ppGpp ${ }_{\text {PstDC3000. }}$ b PSSB728a and (p)ppGpp ${ }_{\text {PssB728a. }}$. DEGs were defined as genes with a $\left|\log _{2} F C\right|$ value $\geq 1$ and a $p$ value $<0.05$. Up and down regulated genes were indicated by red and blue bars, respectively

T3SS were inversely regulated by the retS gene [38]. However, (p) ppGpp in P. syringae regulate transcription expression of T3SS and T6SS in a similar way. Several other genes such as quorum sensing as well as the RpoN also control T6SS in various bacteria [39]. In this study, $28 \mathrm{pu}-$ tative T6SS-associated genes of PstDC3000 and 25 T6SSrelated genes of PssB728a were down-regulated in the (p)ppGpp ${ }_{P s t \mathrm{DC} 3000}$ and (p)ppGpp ${ }_{P S s B 728 a}^{0}$ mutants, respectively (Fig. 5a; Additional file 5: Table S8). These results confirm that (p) ppGpp influences virulence via positive regulation of both T3SS and T6SS in P. syringae.
Cell motility, cell division and exopolysaccharides (EPSs) Motility might enable bacterial cells to avoid environmental stresses [40, 41]. Transcriptomic data showed that 27 genes involved in cell motility were downregulated in PstDC3000 and PssB728a, including type IV pilus biogenesis (pil), flagellar $(f l g)$ and chemotaxis (che) genes (Additional file 3: Table S4). Flagella-mediated motility is an important factor in affecting the virulence of $P$. syringae [42]. The (p) ppGpp positively regulated expression of 16 flagellar-related genes (Additional file 5: Table S9), which is consistent with previous reports that 


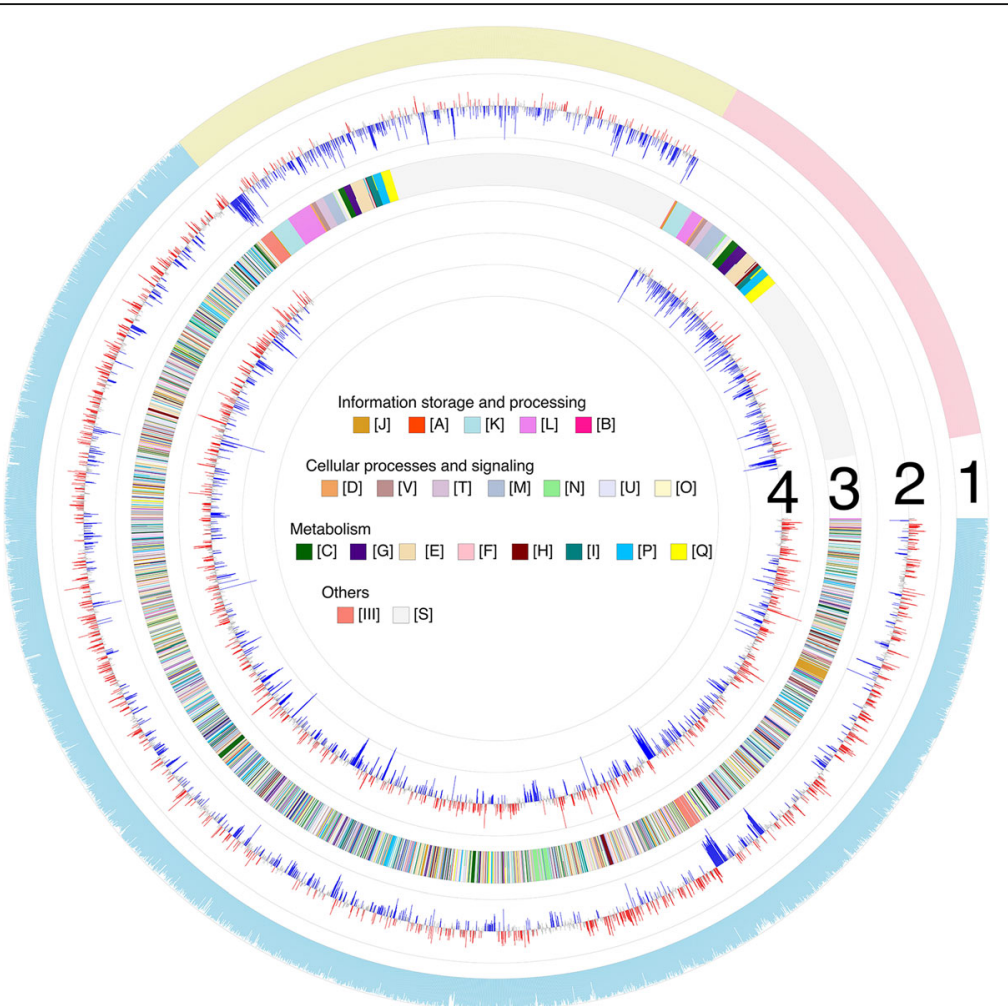

Fig. 3 Circular representation of RNA-seq data. The first ring (outside ring) showed PstDC3000 and PssB728a genome. The sky blue region represents homologues genes between PstDC3000 and PssB728a; the height of the plot represents the percentage of sequence identity (40 to 100\%). The yellow region represents unique genes of PstDC3000. The pink region represents unique genes of PssB728a. The second ring represents $\log _{2} \mathrm{FC}$ of (p)ppGpp ${ }^{0} p_{\text {stDC300o }}$ versus PstDC3000, red and blue bar represent $\log _{2} \mathrm{FC} \geq 1$ and $\log _{2} \mathrm{FC} \leq-1$ with a corrected $p$ value $<0.05$, respectively. The third ring shows that the clusters of orthologous groups (COG) of each genes. Difference function classification is represented by 22 colors. The fourth ring represents $\log _{2} \mathrm{FC}$ of the (p)ppGpp ${ }_{\text {PSSB728a }}^{0}$ versus PsSB728a, red and blue bar represents $\log _{2} \mathrm{FC} \geq 1$ and $\log _{2} \mathrm{FC} \leq-1$ with a corrected $p$ value $<0.05$, respectively

motility of the (p)ppGpp ${ }^{0}{ }_{\text {st }}$ DC3000 and (p)ppGpp ${ }^{0}{ }_{\text {SsB B } 28 \mathrm{a}}$ mutants was suppressed [26, 27].

Previous studies have reported that cells of the (p) $\operatorname{ppGpp}^{0}{ }_{\text {PstDC3000 }}$ and (p)ppGpp ${ }^{0}{ }_{\text {PssB728a }}$ mutants was much longer than those of PstDC3000 and PssB728a in HMM medium and on plant surfaces [26, 27]. Bacterial cells protect themselves by adjusting their cell sizes to adapt to a variety of environment conditions [16, 43]. The products of the ftsA, fts $Q$ and fts $Z$ genes are responsible for controlling cell division and cell wall metabolism [44]. A ring-like macro-molecular complex called the $\mathrm{Z}$ ring is formed by FtsZ polymers, in conjunction with FtsA, ZapA, ZapB and other factors [45]. Bacterial cell size is primarily controlled by the assembly and maturation of FtsZ ring [46]. Mutations in the formation and division of FtsZ ring increase average cell size [4749]. On the other hand, cell division inhibitor (SulA) prevents cell division by directly interacting with FtsZ $[50,51]$, and MinCDE inhibits FtsZ ring assembly, thus blocking the FtsZ ring formation [51, 52]. In this study, RNA-seq data showed that the ftsAQZ cell divisionrelated genes were down-regulated by more than two- fold, whereas the cell division inhibitor gene sulA (pspto_3511, psyr_3284) and $\min C D E$ were up-regulated in the (p)ppGpp ${ }_{\text {PstDC3000 }}^{-}$and (p)ppGpp ${ }_{\text {PssB728a }}$ mutants (Additional file 5: Table S9). These results might explain why cell sizes of the (p)ppGpp ${ }_{P s t \mathrm{DC} 3000}$ and (p)ppGpp ${ }^{0}{ }_{\text {Pss B728a }}$ mutants were increased under such stress conditions.

In addition, EPSs play an important role in both the survival and virulence of $P$. syrinage under stress conditions [53]. P. syringae produces EPS molecules to avoid cell recognition of host plant, resist to desiccation, and enhance its epiphytic fitness [54, 55]. Alginate is one of the EPS molecules reported to be a virulence factor in $P$. syringae and $P$. aeruginosa [56-58]. In this study, RNAseq data showed that 10 genes for alginate biosynthesis, including algAEFGIJK-alg44-alg8 were down-regulated in both the (p)ppGpp ${ }_{\text {PstDC3000 }}^{0}$ and (p)ppGpp ${ }^{0}{ }_{\text {Pss }}$ B728a mutants (Additional file 5: Table S9), indicating that (p) ppGpp activates gene expression of alginate biosynthesis. Heatmap analysis displayed the relative expression profile of genes involved in flagellar, cell division and alginate biosynthesis for (p)ppGpp ${ }_{P s t \mathrm{DC} 3000}$ versus 


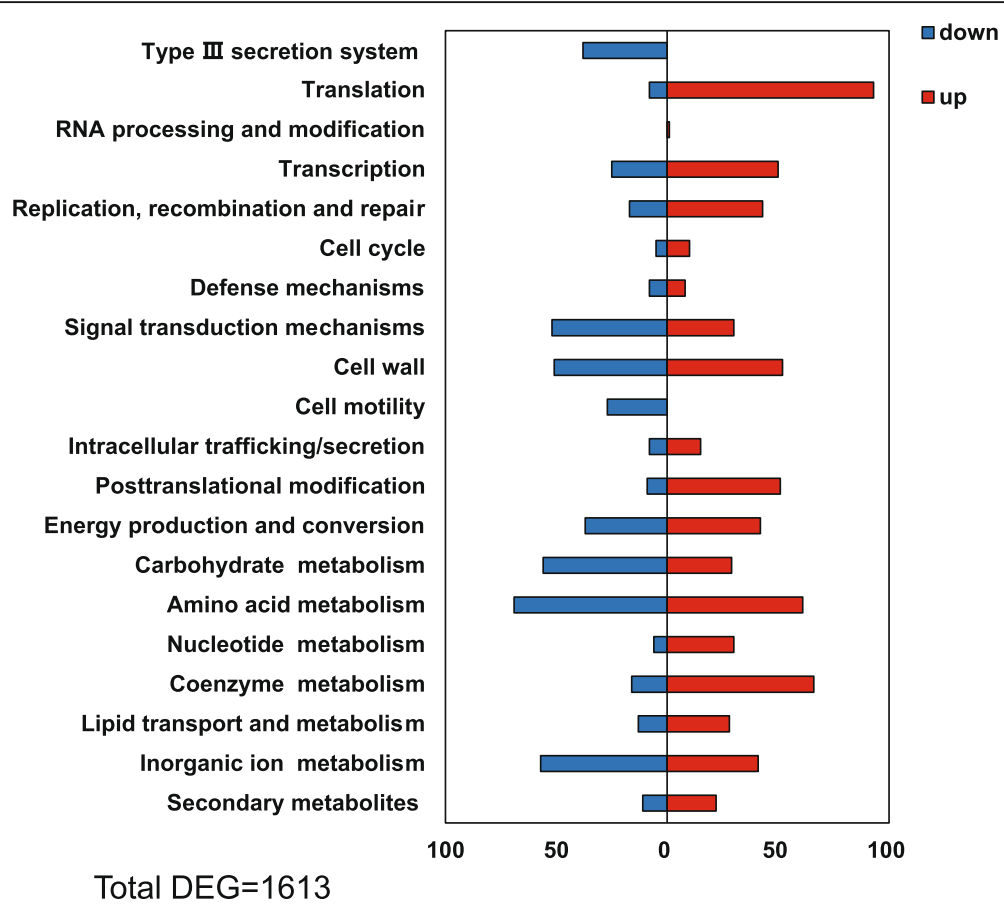

Fig. 4 Functional classification of homologues DEGs regulated by (p) ppGpp in both PstDC3000 and PssB728a based on the clusters of orthologous groups (COGs). DEGs were defined as genes with a $\left|\log _{2} F C\right|$ value $\geq 1$ and a $p$ value $<0.05$. Up and down regulated genes were indicated by red and blue bars, respectively

PstDC3000 and (p)ppGpp ${ }_{\text {PssB728a }}$ versus PssB728a (Fig. 5b). These results suggest that (p) ppGpp acts as an important internal signal to positively regulate virulenceassociated factors in both PstDC3000 and PssB728a.

Negative regulation of basic physiological processes in $P$. syringae

DNA replication, RNA processes and ribosomal protein biosynthesis

As a global regulator, (p) ppGpp of $P$. syringae affects not only virulence factors, but also a variety of basic physiological processes, e.g., DNA replication, RNA processes, ribosome protein synthesis, nucleotide, fatty acid, and amino acid metabolism. In the transcriptomic profiles, only a few genes categorized as replication, recombination and repair were down-regulated in both the (p)ppGpp ${ }_{\text {PstDC3000 and (p)ppGpp }}^{0}{ }_{\text {PssB728a }}$ mutants; whereas most of these genes were up-regulated (Fig. 4), including $\operatorname{din} G, d n a Q, \operatorname{rnh} A$, rep, uvrD, recJ, ssB, ung, and tobB (Fig. 6a; Additional file 5: Table S10). The $\operatorname{din} G$ gene is a DNA damage-inducible gene that will increase significantly after exposure to DNA damage factors [59, 60]. In addition, in E. coli, DNA helicases, DinG, Rep and UvrD work together to promote replication [61]. The single-stranded DNA-binding proteins (SSB) interacts directly with a number of proteins involved in DNA metabolism, such as DinG [60], uracyl-DNA glycosylase [62], nucleases RecJ and SbcB, DNA topoisomerase III
TopB, and helicase RecG and RecQ [63]. Furthermore, DNA polymerase III subunit epsilon DnaQ [64], ribonuclease RnhA [65], and TobB [66] are essential for DNA replication and DNA repair. It is possible that DNA damage might occur in cells due to the absence of (p) ppGpp in P. syringae, thus promoting expression of DNA repair and replication-related genes.

The DEAD box proteins mediate virtually all phases of RNA metabolism, such as RNA processing, transport, degradation, translation and ribosome biogenesis $[67,68]$. The deaD-dbpA-rhlE-rhlB-srmB gene cluster, which encodes an ATP-dependent RNA helicase, is involved in important cellular processes such as mRNA decay or ribosome biogenesis [69]. Among them, SrmB [70] and CsdA (DeaD) [67] are involved in ribosome biogenesis. In this study, we found that gene clusters of pspto_1775-dbpA-rhlE (pspto_4664)-rhlE (pspto_5070)-srmB in PstDC3000 and psyr_3619-dbpA-rhlE-srmB-psyr_4297 in PssB728a were up-regulated in the (p)ppGpp ${ }_{P s t \mathrm{DC} 3000}$ and (p)ppGpp ${ }_{\text {PssB728a }}^{0}$ mutants, respectively (Fig. 6a; Additional file 5: Table S10).

Ribosomes provide the basis for carrying out protein synthesis, thus cell growth [71]. However, protein biosynthesis is the largest consumer of energy during cell proliferation [72]. Therefore, overproduction of ribosomal proteins not only will not benefit the cell, but also could be harmful [73]. Our results showed that 93 translation factors were up-regulated in the (p)ppGpp ${ }_{P s t D C 3000}^{0}$ and 


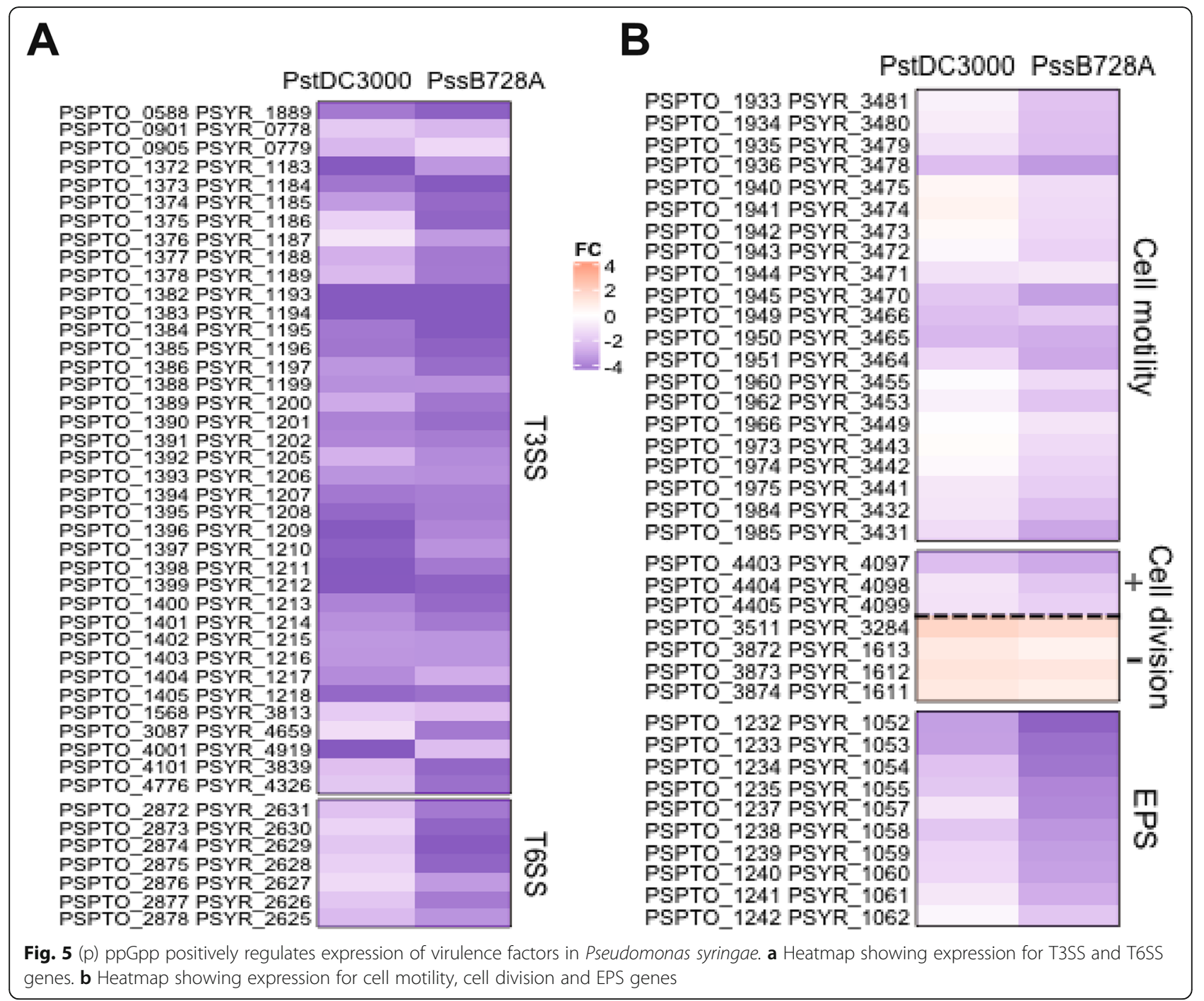

(p)ppGpp ${ }_{P s s B 728 a}$ mutants, including $30 \mathrm{~S}$ and $50 \mathrm{~S}$ ribosome protein synthesis genes (rps, rpm and rpl gene clusters) (Additional file 5: Table S10). Heatmap analysis displayed the expression profile of 33 genes encoding ribosomal proteins (Fig. 6b), indicating that (p) ppGpp negatively regulated ribosomal protein synthesis in HMM.

\section{Nucleotide, fatty acid and amino acid metabolism}

Purine and pyrimidine nucleotides are the basis of cellular activities involved in almost all physiological processes [74]. The purine nucleotide synthesis uses phosphoribosyl pyrophosphate (PRPP) as the initial substrate via both the de novo and salvage biosynthetic pathways [75]. The process of de novo synthesis is divided into two stages, i.e., inosine monophosphate (IMP) synthesis by products of the purBCDEFHKLMN genes, and IMP converted into GMP and AMP by products of the guaAB and purAB genes, respectively $[75,76]$. The adenylate kinase (Adk) catalyzes the conversion of AMP and ATP to two molecules of ADP in the purine nucleotide synthesis pathway $[77,78]$. The first step in the pyrimidine biosynthesis pathway is the formation of carbamyl phosphate (CP) by carA, followed by the formation of UMP via the pyrBCDEF gene cluster [79]. The final product is UMP, which is formed by six steps using carbon dioxide, ammonia, ATP, aspartic acid, PRPP and phosphate [79]. In addition, thymidylate synthase (ThyA) involves a key step in the de novo synthesis of thymidine triphosphate (dTTP) that converts dUMP to dTMP [80]. In this study, RNA-seq data showed that 30 genes of nucleotide metabolism were up-regulated in the (p)ppGpp ${ }_{P s t \mathrm{DC} 3000}$ and (p)ppGpp ${ }^{0}{ }_{\text {Pss B728a }}$ mutants, including purABFLMNTU-3, guaB and $a d k$ genes for purine biosynthesis, and the pyr gene cluster, the tyr $A$ and carA genes for pyrimidine biosynthesis (Additional file 5: Table S11). Heatmap displayed expression profiles of genes involved in purine and pyrimidine biosynthesis in both $P$. syringae systems (Fig. 6c), indicating that (p) 


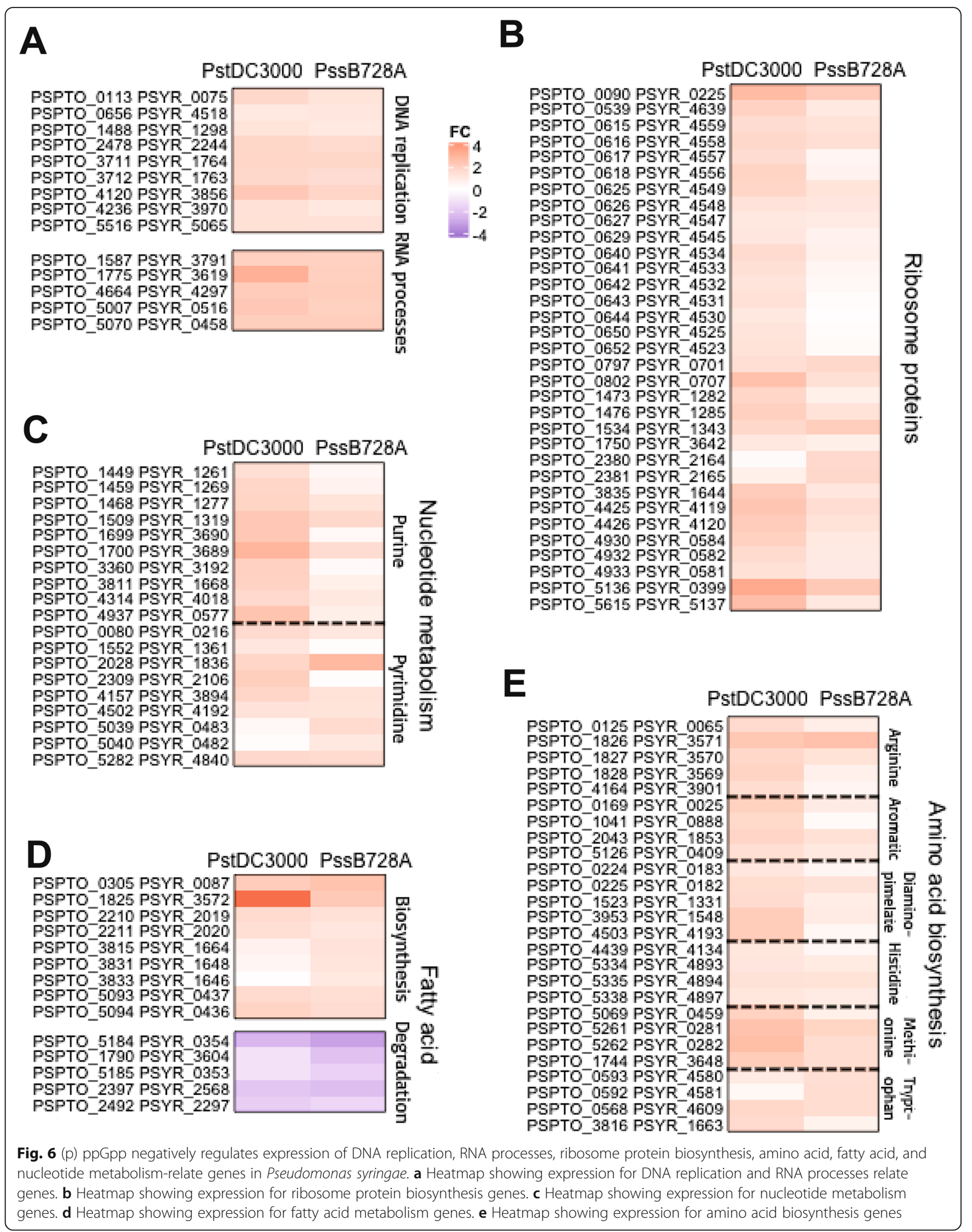


ppGpp inhibited nucleotide metabolism, probably influencing the redistribution of cell resources in P. syringae.

Fatty acid plays an important role in maintaining normal membrane structure and functions under various growth conditions [81]. In this study, our results showed that 13 lipid transport and metabolism-related genes were down-regulated in both the (p)ppGpp ${ }^{0}{ }_{\text {sstDC3000 }}$ and (p)ppGpp ${ }_{\text {Pss }}^{0}{ }_{\text {B } 28 a}$ mutants (Additional file 5: Table S11), including genes encoding acyl-CoA dehydrogenase family protein and short chain dehydrogenase protein involved in the degradation of branched-chain fatty acid [82]. Furthermore, (p) ppGpp negatively regulated 28 fatty acid biosynthesis-related genes, such as $\operatorname{ccs} A$, $\operatorname{des} A$, $a c p P$, $a c c D$, and $f a b A B D$ (Additional file 5: Table S11). Overexpression of the acetyl-CoA carboxylase $(a c c)$ and acetyl-CoA synthetase (acsA) genes could lead to increased fatty acid biosynthesis [83, 84]. A three-carbon precursor malonyl-CoA is required for fatty acid biosynthesis in bacteria, while malonyl-CoA is transferred to the acyl carrier protein (ACP) by malonyl-CoA:ACP acyltransferase (FabD) [85, 86]. In addition, bacteria control the production of unsaturated fatty acids (UFA) or branched-chain fatty acids (BFA) [81] to maintain correct physical state of the membrane lipids [87]. UFAs, as signaling molecules, are involved in important cellular processes, such as cell differentiation and DNA replication $[88,89]$. The $f a b A$ and $f a b B$ genes are require to produce UFAs in E. coli and P. aeruginosa [81], whereas two desaturases DesA and DesB in P. aeruginosa supplement the anaerobic mechanism for UFA synthesis [81]. In P. syringae, (p) ppGpp suppressed fatty acid metabolism by decreasing expression of biosynthesis-related genes, but increasing expression of degradation-related genes (Fig. 6d).

Previous reports showed that the (p)ppGpp ${ }^{0}$ mutants are auxotrophic for 11 amino acids, indicating that $(\mathrm{p})$ ppGpp is required for transcription of amino acid biosynthetic genes [20, 90]. In E. coli, (p) ppGpp directly binds to RNAP to activate transcription of amino acid biosynthesis genes [16, 17]. In this study, 61 upregulated genes were involved in amino acid biosynthesis, including arginine ( $\arg$ ), aromatic (aro), diaminopimelate (dap), histidine (his), methionine (met), tryptophan (trp), whereas 69 down-regulated genes were mainly amino acid $A B C$ transporters in both the (p)ppGpp ${ }^{0}{ }_{\text {st DC3000 }}$ and (p)ppGpp ${ }_{\text {PssB728a }}^{0}$ mutants (Fig. 6e, Additional file 5: Table S11). The inconsistency between our results and previously reported results might be due to that these amino acid biosynthesis genes may be indirectly regulated by (p) ppGpp in P. syringae or due to the experimental conditions used. We also found similar results in E. amylovora (Yang et al. BMC Genom.). Taken together, our results suggested that (p) ppGpp played an important role by inhibiting multiple basic physiological processes, including DNA replication, RNA processes, ribosomal protein biosynthesis, and metabolisms of nucleotide, fatty acid and amino acid, to reallocate cellular resources for virulence-associated gene expression and survival.

\section{Regulation of other cellular processes in $P$. syringae Coenzyme and carbon metabolism}

Coenzyme is an organic non-protein compound that binds with an enzyme to initiate or aid its function [91]. Our results showed that (p) ppGpp suppressed 66 coenzyme metabolism-related genes in both PstDC3000 and PssB728a, including the ribDEF gene cluster, which is involved in riboflavin biosynthesis [92-94], nadACD gene cluster (regulate niacin biosynthesis) and the hemACFHL gene cluster (Additional file 5: Table S12). The latter regulates heme biosynthesis pathway [95], which are essential for the function of diverse proteins, including cytochromes, globins, peroxidases, catalases, and sensors [96]. In contrast, 16 genes involved in coenzyme metabolism were positively controlled by (p) ppGpp, including ssuD (encoding alkanesulfonate monooxygenase), phaG1 (encoding 3-hydroxyacyl-CoA-ACP transferase) and chiI (encoding magnesium chelatase) (Additional file 5: Table S12).

Furthermore, RNA-seq results revealed that (p) ppGpp in PstDC3000 and PssB728a positively regulated 56 genes involved in carbohydrate metabolism, such as mannitol ( $m t l)$ [97], xylose ( $x y l)$ [98] and glycogen $(g l g)$ [99] (Additional file 5: Table S12). On the other hand, 29 carbohydrate metabolism-related genes in PstDC3000 and PssB728a were negatively controlled by (p) ppGpp, including rpiA (encoding ribose 5-phosphate isomerase), $m q o$ (encoding malate:quinone oxidoreductase), and tpiA (encoding triosephosphate isomerase) (Additional file 5: Table S12).

\section{Transcriptional regulators and signal transduction}

Bacterial cells regulate the expression of a series of genes involved in transporter, signal transduction, and transcription in response to changes in the extracellular environment [100]. In this study, (p) ppGpp negatively regulated 50 transcription factors and 30 signal transduction-related genes. These genes encode carbon starvation protein CstA, BolA-like protein, phosphohistidine phosphatase SixA, transcriptional activator MetR, alkylphosphonate utilization operon protein $\mathrm{PhnA}$, and transcriptional regulator NrdR (Additional file 5: Table S13). The CstA is involved in nutrient scavenging and peptide transport $[101,102]$. The BolA regulates expression of many cell wall proteins and is partially responsible for the coccoid morphology of stationary phase cells in E. coli $[19,103]$. Phosphorylation of histidine and aspartate is very important in bacterial regulatory 
systems, and SixA (signal inhibitor $\mathrm{X}$ ) is one of the earliest discovered phosphohistidine phosphatases [104]. On the other hand, 52 signal transduction-related genes and 25 transcription factors were down-regulated in both the (p)ppGpp ${ }_{\text {PstDC3000 }}^{0}$ and (p)ppGpp ${ }_{\text {PssB728a }}$ mutants. These genes included carbon storage regulator CsrA2, diguanylate cyclase, $\mathrm{HrpL}$ and ribose operon repressor RbsR (Additional file 5: Table S13). These results indicated that (p) ppGpp positively and negatively controlled transcription factors and signal transduction-related genes, thereby regulating global gene expression for adapting to changes in the extracellular environments.

\section{Differential regulation by (p) ppGpp in PstDC3000 and PssB728a}

Comparative transcriptomic analysis also identified unique and homologous DEGs similarly or inversely regulated by (p) ppGpp in PstDC3000 and PssB728a (Table 1). Phytotoxin is very important for $P$. syringae pathogenesis. However, different phytotoxins are produced in PstDC3000 and PssB728a. PstDC3000 produces the non-host-specific and chlorosis-inducing coronatine (COR) [105], whereas
PssB728a produces syringomycins and syringopeptins, which could form pores in plasma membranes, resulting in necrotic symptoms [106]. Our data showed that coronatine (corR and corS) and coronamic acid synthetase genes (cmaBCTU gene cluster) in the (p)ppGpp ${ }_{P s t D C 3000}^{0}$ mutant, and syringomycin synthesis genes (syrB1CDEFP gene cluster) in the $\operatorname{ppGpp}^{0}{ }_{\text {PssB728a }}$ mutant were all down-regulated (Table 2). These results indicated that (p) ppGpp positively activate toxin gene expression to promote bacterial virulence in both PstDC3000 and PssB728a.

Previous report showed that PstDC3000 carried three putative T6SS clusters (HSI-I, HSI-II, and ppkA), whereas PssB728a only carried two (HIS-I and $p p k A$ ) [30]. In this study, only 7 homologous genes belonging to the $p p k A$ locus were down-regulated in both the (p)ppGpp ${ }^{0}{ }_{s t \mathrm{DC} 3000}$ and (p)ppGpp ${ }_{P s s B 728 a}$ mutants (Fig. 5a). Fifteen T6SS genes on HSI-I cluster in PssB728a, and 18 T6SS genes on HSI-II cluster, but no genes on HSI-I in PstDC3000, were positively regulated by (p) ppGpp (Table 3), indicating that different T6SSs may be regulated differently by (p) ppGpp in PstDC3000 and PssB728a. Furthermore, we found that some homologous genes in PstDC3000 and PssB728a were

Table 1 Differential gene regulation by (p) ppGpp in PstDC3000 and PssB728a

\begin{tabular}{|c|c|c|c|c|c|c|}
\hline \multirow[b]{2}{*}{ Symbol } & \multirow[b]{2}{*}{ Functional classification (COGs) } & \multirow[t]{2}{*}{$\begin{array}{l}\text { Homolog genes } \\
\text { inversely regulated }\end{array}$} & \multicolumn{2}{|c|}{$\begin{array}{l}\text { PstDC3000 (unique } \\
\text { genes) }\end{array}$} & \multicolumn{2}{|c|}{$\begin{array}{l}\text { PssB728a (unique } \\
\text { genes) }\end{array}$} \\
\hline & & & Up & Down & Up & Down \\
\hline & Type III secretion system & 0 & 0 & 37 & 0 & 7 \\
\hline J & Translation, ribosomal structure and biogenesis & 4 & 0 & 2 & 0 & 3 \\
\hline A & RNA processing and modification & 0 & 0 & 0 & 0 & 0 \\
\hline K & Transcription & 13 & 9 & 8 & 1 & 4 \\
\hline L & Replication, recombination and repair & 4 & 8 & 15 & 0 & 8 \\
\hline D & Cell cycle control, cell division, chromosome partitioning & 2 & 1 & 1 & 0 & 1 \\
\hline V & Defense mechanisms & 1 & 0 & 11 & 0 & 6 \\
\hline $\mathbf{T}$ & Signal transduction mechanisms & 16 & 3 & 10 & 0 & 9 \\
\hline M & Cell wall/membrane/envelope biogenesis & 14 & 1 & 8 & 2 & 14 \\
\hline $\mathbf{N}$ & Cell motility & 5 & 0 & 1 & 0 & 3 \\
\hline U & Intracellular trafficking, secretion, and vesicular transport & 15 & 1 & 1 & 1 & 9 \\
\hline 0 & Posttranslational modification, protein turnover, chaperones & 4 & 0 & 5 & 0 & 2 \\
\hline $\mathrm{C}$ & Energy production and conversion & 15 & 0 & 7 & 1 & 3 \\
\hline G & Carbohydrate transport and metabolism & 9 & 0 & 9 & 1 & 8 \\
\hline $\mathrm{E}$ & Amino acid transport and metabolism & 20 & 1 & 15 & 1 & 9 \\
\hline $\mathrm{F}$ & Nucleotide transport and metabolism & 1 & 0 & 3 & 0 & 0 \\
\hline $\mathbf{H}$ & Coenzyme transport and metabolism & 6 & 0 & 2 & 0 & 1 \\
\hline I & Lipid transport and metabolism & 9 & 3 & 3 & 1 & 4 \\
\hline $\mathbf{P}$ & Inorganic ion transport and metabolism & 16 & 0 & 10 & 0 & 4 \\
\hline Q & Secondary metabolites biosynthesis, transport and catabolism & 3 & 0 & 16 & 2 & 19 \\
\hline S & Function unknown & 101 & 64 & 199 & 29 & 145 \\
\hline Total & & 258 & 91 & 362 & 39 & 259 \\
\hline
\end{tabular}

COG Clusters of orthologous groups (http://www.ncbi.nlm.nih.gov/COG). See methods for description 
Table $\mathbf{2}$ List of phytotoxin genes differentially regulated by (p) ppGpp in PstDC3000 and PssB728a

\begin{tabular}{|c|c|c|c|}
\hline Locus tag & Description & (p)ppGpp ${ }_{\text {PstDC3000 }} /$ PstDC3000 & (p)ppGpp ${ }_{\text {PssB728a }} /$ PssB728a \\
\hline \multicolumn{4}{|l|}{ DC3000 } \\
\hline \multicolumn{4}{|l|}{ Phytotoxin } \\
\hline \multicolumn{4}{|l|}{ Coronatine } \\
\hline PSPTO_4704 & DNA-binding response regulator CorR & -2.59 & I \\
\hline PSPTO_4705 & sensor histidine kinase CorS & -1.81 & I \\
\hline \multicolumn{4}{|c|}{ Coronamic acid } \\
\hline PSPTO_4710 & coronamic acid synthetase $\mathrm{CmaB}$ & -2.02 & I \\
\hline PSPTO_4711 & coronamic acid synthetase $\mathrm{CmaC}$ & -1.53 & I \\
\hline PSPTO_4712 & coronamic acid synthetase, CmaT & -1.68 & I \\
\hline PSPTO_4714 & CmaU protein & -1.15 & I \\
\hline \multicolumn{4}{|c|}{ B728a Syringomycin } \\
\hline PSYR_2607 & regulatory protein SyrF & I & -2.16 \\
\hline PSYR_2608 & amino acid adenylation SyrE & I & -1.81 \\
\hline PSYR_2609 & Alpha/beta hydrolase fold SyrC & I & -1.34 \\
\hline PSYR_2611 & amino acid adenylation SyrB1 & I & -1.23 \\
\hline PSYR_2612 & SyrP protein & I & -2.97 \\
\hline PSYR_2613 & cyclic peptide transporter SyrD & / & -2.03 \\
\hline
\end{tabular}

DEGs were differentially expressed genes in the (p)ppGpp ${ }^{0}{ }_{\text {StDC3000 }}$ and (p)ppGpp ${ }_{\text {PssB728a }}$ with $p$-value $<0.05$ between the WT and the ppGpp ${ }^{0}$ mutants. '/' represents that gene is not present

inversely regulated by (p)ppGpp. For example, cell motility genes (pilF, fliQ, flgHIG) and cobalamin biosynthetic genes (cobOPST) were up-regulated in the (p)ppGpp ${ }_{P s t \mathrm{DC} 3000}^{0}$ mutant, but down-regulated in the (p) ppGpp $^{0}{ }_{P s s B 728 \mathrm{a}} \mathrm{mu}-$ tant. In contrast, nitrogen regulation (ntrBC) and general secretion pathway (GSP) (gspDEFGHIJ) genes were downregulated in the (p)ppGpp ${ }_{P s t \mathrm{DC} 3000}$ mutant, but upregulated in the (p)ppGpp ${ }_{\text {PssB728a }}^{0}$ mutant (Table 4).

\section{Conclusions}

The model presented in Fig. 7 is based on our global transcription data as well as previously reported results in PstDC3000 and Pss728a [16, 17]. In HMM, the RelA/ SpoT/FpRel systems are activated in PstDC3000 and PssB728a, leading to accumulation of (p)ppGpp. Thereafter, the (p)ppGpp-mediated stringent response indirectly promotes alternative sigma factor activities, such as RpoN and HrpL, leading to the expression of T3SS and other virulence factors, as well as stress-related genes. In both PstDC3000 and PssB728a, (p) ppGpp suppresses biosynthesis of DNA replication, RNA processes, ribosome proteins, nucleotide metabolism, amino acid metabolism and fatty acid metabolism and other basic physical processes, and at the same time, activates the expression of T3SS, T6SS, cell motility, cell division, EPS and phytotoxin to promote virulence and survival.

\section{Methods}

\section{Bacterial strains and growth conditions}

The wild-type PstDC3000 and its relA/spoT/fpRel triple mutant ((p)ppGpp $\left.{ }_{\text {PstDC3000 }}\right)$, and the wild-type PssB728a and its relA/spoT double mutant ( $\left.(\mathrm{p}) \mathrm{ppGpp}^{0}{ }_{\text {PssB728a }}\right)$ $[26,27]$ were routinely cultured on King's medium $B$ (KB) plate, or $5 \mathrm{ml}$ of fresh $\mathrm{KB}$ broth at $28^{\circ} \mathrm{C}$ with shaking at $250 \mathrm{rpm}$. The hrp-inducing medium (HMM) supplemented with $10 \mathrm{mM}$ fructose as carbon source was used for RNA isolation [26, 27, 107]. Bacterial growth was monitored by measuring absorbance of cell suspensions at $600 \mathrm{~nm}$. Antibiotics were supplied at the following final concentrations: rifampicin, $100 \mu \mathrm{g} \mathrm{ml}^{-1}$ and kanamycin, $50 \mu \mathrm{g} \mathrm{ml}^{-1}$.

\section{RNA extraction for RNA-seq and CDNA synthesis}

Overnight cultures of the bacterial strains were collected by centrifugation, and washed with HMM for three time. The suspensions were adjusted to $\mathrm{OD}_{600}=0.2$ in $\mathrm{HMM}$ and incubated in $5 \mathrm{ml} \mathrm{HMM}$ at $18{ }^{\circ} \mathrm{C}$ for $3 \mathrm{~h}$. Four $\mathrm{ml}$ of RNA protect reagent (Qiagen, Hilden, Germany) was added to $2 \mathrm{ml}$ of bacterial culture mixed by vortex and incubated at room temperature for $5 \mathrm{~min}$. Cells were harvested by centrifugation and total RNAs were extracted using $\mathrm{RNeasy}^{\circ}$ mini kit (Qiagen) according to the manufacturer's instructions. DNase I treatment was performed with TURBO DNA-free kit (Ambion, TX, USA). The quantity and quality of RNA samples was 
Table 3 List of T6SS genes differentially regulated by (p) ppGpp in PstDC3000 and PssB728a

\begin{tabular}{|c|c|c|c|}
\hline Locus tag & Description & (p)ppGpp ${ }_{\text {PstDC3000 }} /$ PstDC3000 & (p)ppGpp ${ }_{\text {PssB728a }} /$ PssB728a \\
\hline \multicolumn{4}{|l|}{ DC3000 } \\
\hline PSPTO_2539 & secreted protein Hcp-1 & -1.37 & I \\
\hline PSPTO_2550 & hypothetical protein PSPTO_2550 & -1.83 & I \\
\hline PSPTO_2553 & hypothetical protein PSPTO_2553 & -1.38 & I \\
\hline PSPTO_4385 & Rhs element Vgr protein & -1.26 & I \\
\hline PSPTO_5415 & Rhs element Vgr protein & -1.79 & I \\
\hline PSPTO_5416 & serine/threonine protein kinase & -1.63 & I \\
\hline PSPTO_5417 & serine/threonine phosphoprotein phosphatase & -2.81 & I \\
\hline PSPTO_5418 & hypothetical protein PSPTO_5418 & -2.85 & I \\
\hline PSPTO_5419 & hypothetical protein PSPTO_5419 & -2.85 & I \\
\hline PSPTO_5420 & hypothetical protein PSPTO_5420 & -2.48 & I \\
\hline PSPTO_5421 & lipoprotein & -2.84 & I \\
\hline PSPTO_5422 & FHA domain-containing protein & -2.25 & I \\
\hline PSPTO_5423 & hypothetical protein PSPTO_5423 & -2.01 & I \\
\hline PSPTO_5424 & sigma-54 dependent transcriptional regulator & -1.67 & I \\
\hline PSPTO_5425 & ClpB protein & -1.82 & I \\
\hline PSPTO_5426 & hypothetical protein PSPTO_5426 & -1.96 & I \\
\hline PSPTO_5427 & hypothetical protein PSPTO_5427 & -2.16 & I \\
\hline PSPTO_5430 & hypothetical protein PSPTO_5430 & -1.75 & I \\
\hline PSPTO_5435 & secreted protein Hcp-2 & -1.29 & I \\
\hline PSPTO_5436 & Rhs element Vgr protein & -2.59 & I \\
\hline PSPTO_5437 & hypothetical protein PSPTO_5437 & -2.91 & I \\
\hline PSPTO_5438 & Rhs family protein & -1.77 & I \\
\hline \multicolumn{4}{|l|}{ B728a } \\
\hline PSYR_1935 & hypothetical protein PSYR_1935 & l & -1.04 \\
\hline PSYR_2632 & virulence protein SrfB & I & -3.45 \\
\hline PSYR_2633 & hypothetical protein PSYR_2633 & I & -1.76 \\
\hline PSYR_4955 & hypothetical protein PSYR_4955 & l & -1.57 \\
\hline PSYR_4956 & hypothetical protein PSYR_4956 & l & -2.04 \\
\hline PSYR_4957 & hypothetical protein PSYR_4957 & l & -2.66 \\
\hline PSYR_4958 & ATPase AAA & l & -3.3 \\
\hline PSYR_4959 & hypothetical protein PSYR_4959 & l & -3.23 \\
\hline PSYR_4960 & hypothetical protein PSYR_4960 & I & -3.61 \\
\hline PSYR_4961 & hypothetical protein PSYR_4961 & I & -4.21 \\
\hline PSYR_4962 & hypothetical protein PSYR_4962 & I & -3.88 \\
\hline PSYR_4963 & hypothetical protein PSYR_4963 & l & -3.12 \\
\hline PSYR_4964 & OmpA/MotB protein & l & -2.83 \\
\hline PSYR_4965 & hypothetical protein PSYR_4965 & l & -4.22 \\
\hline PSYR_4966 & ImpA-like protein & l & -3.72 \\
\hline PSYR_4967 & hypothetical protein PSYR_4967 & l & -2.8 \\
\hline PSYR_4974 & Rhs element Vgr protein & l & -1.91 \\
\hline PSYR_4983 & Rhs element Vgr protein & l & -2.54 \\
\hline
\end{tabular}

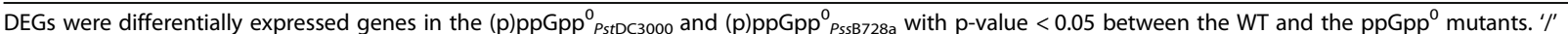
represents that gene is not present or not significantly regulated 
Table 4 List of homologous genes regulated by (p) ppGpp in opposite ways in PstDC3000 and PssB728a

\begin{tabular}{|c|c|c|c|c|}
\hline \multicolumn{2}{|l|}{ Locus tag } & \multirow[t]{2}{*}{ Gene description } & \multirow[t]{2}{*}{$\begin{array}{l}\text { (p)ppGpp }{ }^{0}{ }_{\text {stDC }} 0000 \\
\text { /PstDC3000 }\end{array}$} & \multirow[t]{2}{*}{$\begin{array}{l}\text { (p)ppGpp }{ }^{0}{ }_{\text {ssB728a }} \\
\text { /PssB728a }\end{array}$} \\
\hline DC3000 & B728A & & & \\
\hline PSPTO_1432 & PSYR_1246 & type IV pilus biogenesis protein PilF & 1.29 & -0.85 \\
\hline PSPTO_1940 & PSYR_3475 & flagellar basal-body rod protein FlgG & 0.45 & -1.27 \\
\hline PSPTO_1941 & PSYR_3474 & flagellar L-ring protein FlgH & 0.61 & -1.36 \\
\hline PSPTO_1973 & PSYR_3443 & flagellar biosynthetic protein FliQ & 0.22 & -1.36 \\
\hline PSPTO_1942 & PSYR_3473 & flagellar P-ring protein Flgl & 0.36 & -1.43 \\
\hline PSPTO_1713 & PSYR_3676 & cobyric acid synthase CobQ & 1.82 & -0.20 \\
\hline PSPTO_1714 & PSYR_3675 & $\begin{array}{l}\text { cobinamide kinase/cobinamide phosphate } \\
\text { guanylyltransferase CobP }\end{array}$ & 1.56 & -0.57 \\
\hline PSPTO_1717 & PSYR_3672 & cobalamin (5 $\backslash^{\prime}$-phosphate) synthase CobS & 1.02 & -1.04 \\
\hline PSPTO_1715 & PSYR_3674 & $\begin{array}{l}\text { nicotinate-nucleotide--dimethylbenzimidazole } \\
\text { phosphoribosyltransferase CobT }\end{array}$ & 1.66 & -1.08 \\
\hline PSPTO_0352 & PSYR_4822 & nitrogen regulation protein $\mathrm{NR}(\mathrm{I}) \mathrm{NtrC}$ & -0.60 & 1.61 \\
\hline PSPTO_0353 & PSYR_4821 & nitrogen regulation protein $\mathrm{NtrB}$ & -0.29 & 2.47 \\
\hline PSPTO_3315 & PSYR_3149 & general secretion pathway protein G, GspG & -0.67 & 1.69 \\
\hline PSPTO_3314 & PSYR_3148 & general secretion pathway protein $\mathrm{H}, \mathrm{GspH}$ & -0.70 & 1.40 \\
\hline PSPTO_3317 & PSYR_3151 & general secretion pathway protein $\mathrm{E}$ & -0.36 & 1.36 \\
\hline PSPTO_3316 & PSYR_3150 & general secretion pathway protein F, GspE & -0.69 & 1.34 \\
\hline PSPTO_3313 & PSYR_3147 & general secretion pathway protein I, Gspl & -0.93 & 1.09 \\
\hline PSPTO_3312 & PSYR_3146 & general secretion pathway protein J, GspJ & -1.01 & 0.80 \\
\hline PSPTO_3307 & PSYR_3141 & general secretion pathway protein D, GspD & -1.18 & 0.11 \\
\hline
\end{tabular}

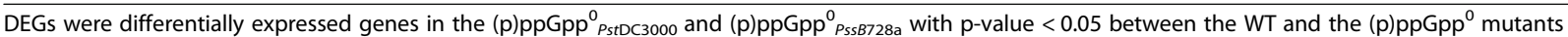

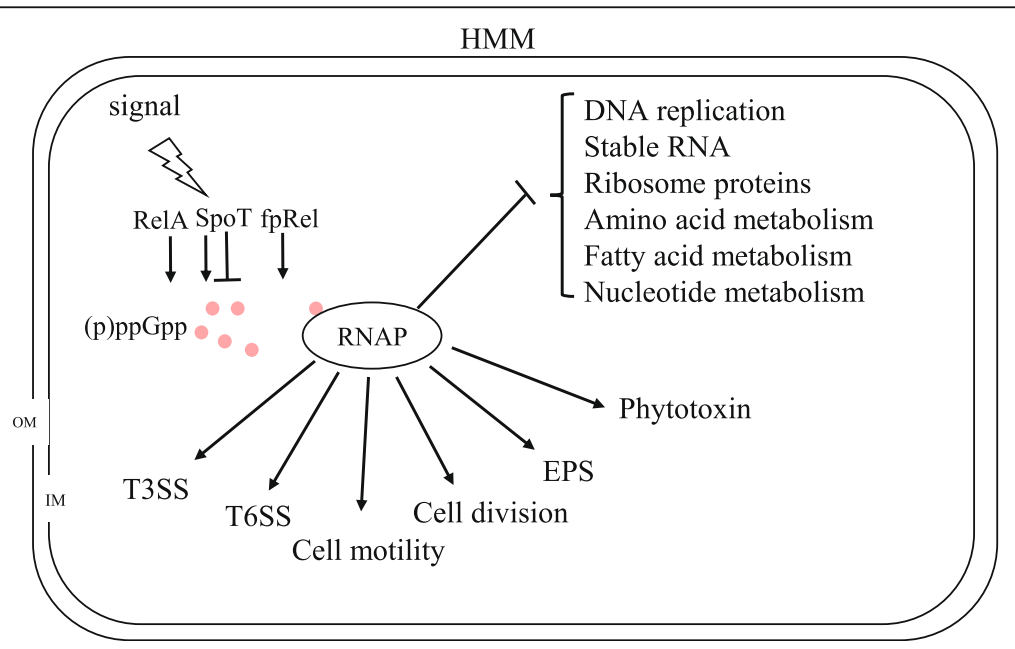

Fig. 7 Proposed model illustrating the global effect of (p) ppGpp in Pseudomonas syringae. (p) ppGpp binds to RNAP and switches transcription from growth-related genes to virulence factors and stress relate genes. Symbols: $\downarrow$, positive effect; $\perp$, negative effect; RNAP, RNA polymerase 
determined using Nano-drop ND100 spectrophotometer (Nano-Drop Technologies; Wilmington, DE, USA), and/ or using Agilent RNA 6000 Nano Chip Bioanalyzer (Agilent, Santa Clara, CA, USA).

\section{Illumina sequencing and RNA-seq analysis}

Library construction and sequencing of three biological samples of PstDC3000, PssB728a and their mutants using the Illumina HiSeq 2500 (Illumina, San Diego, CA, USA) were performed by the Keck Center at the University of Illinois at Urbana-Champaign (UIUC). A total of twelve stranded libraries were constructed using TruSeq Stranded RNA Sample Prep kit following the manufacturer's instructions (Illumina, San Diego, CA, USA). The sequence reads were aligned to the genome of PstDC3000 [108] and PssB728a [6] using Bowtie 0.12.7 [109]. Samtools and bedtools were performed for getting the read counts per CDS. Normalized log2-based count per million values $\left(\log _{2} \mathrm{CPM}\right)$ were calculated after trimmed mean of $\mathrm{M}$ values (TMM) normalization in the edge $R$ package $[110,111]$.

To examine the gene expression dynamics among all the samples, a PCA was conducted by using prcomp in $\mathrm{R}$. To perform normalization and statistical analysis on the raw read counts, the $R$ package edge $R$ was used as described previously $[110,111]$. DEGs were defined as genes with a $\mid \log _{2} \mathrm{FC}$ (fold change) $\mid$ value $\geq 1$ and a corrected $p$ value $<0.05$ from three biological samples. To visualize overall expression pattern of individual genes, the MA plots ( $\log _{2} \mathrm{FC}$ versus Average $\log _{2} \mathrm{CPM}$; FC, fold change; $C P M$, counts per million reads) were generated. For functionally categorization of DEGs using COGs, protein sequence of all coding genes in PstDC3000 (accession \#: AE016853.1) and PssB728a (accession \#: CP000075.1) were downloaded from NCBI (https://www.ncbi.nlm.nih. gov/). The two FASTA protein files were used as input for protein annotation using eggNOG-mapper (http://eggnogdb.embl.de/\#/app/emapper). COG information for DEGs was extracted from eggNOG output file. In addition, genes involved in type III secretion system (T3SS) were manually grouped into an additional orthologous categorization. The RNA-seq data files have been submitted to Gene Expression Omnibus (GEO) at the National Center for Biotechnology Information (NCBI) with an accession number GSE143325.

\section{Identification of homologous and unique genes in PstDC3000 and PssB728a}

Coding sequences in the genomes of PstDC3000 and PssB728a were downloaded from the NCBI database. BLASTP cutoff scores of $\mathrm{E}<10^{-2}$ and $40 \%$ identity were used to distinguish homologues and unique genes between PstDC3000 and PssB728a.

\section{Quantitative real-time PCR (qRT-PCR)}

For qRT-PCR, $1 \mu \mathrm{g}$ of RNA was reverse transcribed to cDNA following the manufacturer's instruction for the SperScript ${ }^{\text {tu }}$ III Reverse Transcriptase (Invitrogen, Carlsbad, CA, USA). Concentration of cDNA was adjusted to $100 \mathrm{ng} / \mu \mathrm{l}$ as template and the Power Up SYBR ${ }^{\circ}$ Green PCR master mix (Applied Biosystems, CA, USA) was used for qRT-PCR to detect gene expression of selected genes. The qRT-PCR amplifications were conducted in the StepOnePlus Real-Time PCR system (Applied Biosystems) under the following conditions: $50^{\circ} \mathrm{C}$ for $2 \mathrm{~min}$, and $95^{\circ} \mathrm{C}$ for $2 \mathrm{~min}$ followed by 40 cycles of $95^{\circ} \mathrm{C}$ for 15 $\mathrm{s}$ and $60^{\circ} \mathrm{C}$ for $1 \mathrm{~min}$. The $g l t B$ gene was used as an endogenous control to calculate relative quantification $\left(\Delta \Delta C_{t}\right)$ [112]. All primers are listed in Additional file 6. The experiment was repeated and three biological replicates were performed for each gene. Comparative $\Delta \Delta C_{t}$ method was used to analyze the data and statistical analysis was performed using student's t test with $P<0.05$.

\section{Supplementary information}

Supplementary information accompanies this paper at https://doi.org/10. 1186/s12864-020-6701-2.

\begin{abstract}
Additional file 1: Figure S1 Heatmap. (A) (p)ppGpp ${ }^{0}{ }_{s t} \mathrm{Dc} 3000$ versus PstDC3000: 1886 differentially expressed genes (DEGs). (B) (p)ppGpp ${ }_{\text {PssB728a }}$ versus PssB728a: 1562 DEGs. Up and down regulated genes were indicated by red and blue lines. Figure S2 MA plots. (A)

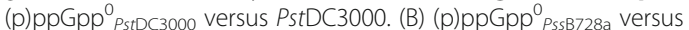
PssB728a. M: $\log _{2}$ FC, A: Average $\log _{2} C P M$, counts per million reads. Dots between two purple lines represent $|\log 2 \mathrm{FC}|$ value $\leq 1$, and outside dots represent $\left|\log _{2} \mathrm{FC}\right|$ value $\geq 1$. Up and down regulated genes were indicated by red and blue dot with $p$ value $<0.05$, black dot represents no signification difference and $p$ value $>0.05$.
\end{abstract}

Additional file 2: Table S1. List of differentially expressed genes (DEGs) of (p)ppGpp ${ }^{0}{ }_{\text {stDC } 3000}$ versus PstDC3000. Table S2. List of DEGs of

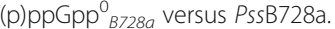

Additional file 3: Table S3. List of homologues and unique genes via comparative analysis of PstDC3000 and PssB728a genomes. Table S4. List of homologues genes in both PstDC3000 and PssB728a regulated by (p) ppGpp in a similar way. Table S5. List of homologues genes in both PstDC3000 and PssB728a inversely regulated by (p)ppGpp.

Additional file 4: Table S6. List of unique genes in PstDC3000 regulated by (p)ppGpp. Table S7. List of unique genes of PssB728a regulated by (p)ppGpp.

Additional file 5: Table S8. List of differentially expressed genes (DEGs) related to type III secretion system (T3SS) and type VI secretion system (T6SS). Table S9. List of DEGs related to cell motility, division, and exopolysaccharides (EPS). Table S10. List of DEGs related to DNA replication, RNA processes and ribosomal protein biosynthesis. Table S11. List of DEGs related to nucleotide, amino acid and fatty acid metabolism. Table S12. List of DEGs related to coenzyme and carbon metabolism. Table S13. List of DEGs related to signal transduction and transcription.

Additional file 6: Table S14. Primers for qRT-PCR used in this study.

\section{Abbreviations}

(p)ppGpp: guanosine tetra/pentaphosphate; PstDC3000: P. syringae pv. tomato DC3000; PssB728a: P. syringae pv. syringae B728a; RSH: RelA-SpoT homologue; RNAP: RNA polymerase; TMM: Trimmed mean of M values; CPM: Counts per million reads; FC: Fold change; GEO: Gene Expression Omnibus; PCA: Principal component analysis; COGs: Clusters of orthologous 
groups; DEGs: Differentially expressed genes; T3SS: Type III secretion system; T6SS: Type VI secretion system; EPSs: Exopolysaccharides; GSP: General secretion pathway

\section{Acknowledgements}

Not applicable.

\section{Authors' contributions}

Y. Z. and B. H. designed the research. J. L., M. Y., T. C., Y. T., and J. H. L performed the research and analyzed the data. J. L., M. Y., and Y. Z. wrote the paper. All authors have read and approved the manuscript.

\section{Funding}

This project was supported by the Agriculture and Food Research Initiative Competitive Grants Program Grant no. 2016-67013-24812 from the USDA National Institute of Food and Agriculture and USDA-Hatch Project ILLU-802913 (YFZ). JL would like to thank the financial support from the China Scholarship Council. The funders had no role in study design, data collection and analysis, decision to publish, or preparation of the manuscript.

\section{Availability of data and materials}

The datasets generated during the current study are available in the Gene Expression Omnibus (GEO) at the National Center for Biotechnology Information (NCBI) with an accession number GSE143325

\section{Ethics approval and consent to participate}

Not applicable.

\section{Consent for publication}

Not applicable.

\section{Competing interests}

The authors declare that they have no competing interests.

Received: 14 January 2020 Accepted: 25 March 2020

Published online: 10 April 2020

\section{References}

1. Horst RK. Westcott's plant disease handbook. 5th ed. New York: Chapman \& Hall; 1990.

2. Hwang MSH, Morgan RL, Sarkar SF, Wang PW, Guttman DS. Phylogenetic characterization of virulence and resistance phenotypes of Pseudomonas syringae. Appl Environ Microbiol. 2005;71(9):5182-91.

3. Ishiga $Y$, Ichinose $Y$. Pseudomonas syringae pv. tomato OxyR is required for virulence in tomato and Arabidopsis. Mol Plant-Microbe Interact. 2016;29(2): 119-31.

4. Preston GM. Pseudomonas syringae pv. tomato: the right pathogen, of the right plant, at the right time. Mol Plant Pathol. 2000;1(5):263-75.

5. Xin XF, He SY. Pseudomonas syringae pv. tomato DC3000: a model pathogen for probing disease susceptibility and hormone signaling in plants. Annu Rev Phytopathol. 2013;51:473-98.

6. Feil H, Feil WS, Chain P, Larimer F, Dibartolo G, et al. Comparison of the complete genome sequences of Pseudomonas syringae pv. syringae B728a and Pseudomonas syringae pv. tomato DC3000. Proc Natl Acad Sci U S A. 2005:102(31):11064-9.

7. Yu X, Lund S, Scott R, Greenwald J, Records A, Nettleton D, et al. Transcriptional responses of Pseudomonas syringae to growth in epiphytic versus apoplastic leaf sites. Proc Natl Acad Sci USA. 2013;110(5):E425-34.

8. Ichinose Y, Taguchi F, Mukaihara T. Pathogenicity and virulence factors of Pseudomonas syringae. J Gen Plant Pathol. 2013;79(5):285-96.

9. Lindeberg $M$, Cunnac S, Collmer A. Pseudomonas syringae type III effector repertoires: last words in endless arguments. Trends Microbiol. 2012;20(4): $199-208$.

10. Nomura K, Melotto M, He SY. Suppression of host defense in compatible plant-Pseudomonas syringae interactions. Curr Opin Plant Biol. 2005;8(4): 361-8.

11. Alarcón-Chaidez FJ, Keith L, Zhao Y, Bender CL. RpoN (ఠ54) is required for plasmid-encoded coronatine biosynthesis in Pseudomonas syringae. Plasmid. 2003:49(2):106-17.

12. Tang $X$, Xiao $Y$, Zhou JM. Regulation of the type III secretion system in phytopathogenic bacteria. Mol Plant-Microbe Interact. 2006;19(11):1159-66.
13. Ancona V, Lee JH, Chatnaparat T, Oh J, Hong Jl, Zhao YF. The bacterial alarmone (p) ppGpp activates the type III secretion system in Erwinia amylovora. J Bacteriol. 2015;197(8):1433-43.

14. Anderson JC, Wan Y, Kim YM, Pasa-Tolic L, Metz TO, Peck SC. Decreased abundance of type III secretion system-inducing signals in Arabidopsis mkp1 enhances resistance against Pseudomonas syringae. Proc Natl Acad Sci U S A. 2014;111(18):6846-51.

15. Kalia D, Merey G, Nakayama S, Zheng Y, Zhou J, Luo Y, Guo M, Roembke BT, Sintim HO. Nucleotide, c-di-GMP, c-di-AMP, cGMP, cAMP, (p) ppGpp signaling in bacteria and implications in pathogenesis. Chem Soc Rev. 2013; 42:305-41.

16. Dalebroux ZD, Swanson MS. ppGpp: magic beyond RNA polymerase. Nat Rev Microbiol. 2012:10:203-12.

17. Dalebroux ZD, Svensson SL, Gaynor EC, Swanson MS. ppGpp conjures bacterial virulence. Microbiol Mol Biol Rev. 2010;74(2):171-99.

18. Magnusson LU, Farewell A, Nystrom T. ppGpp: a global regulator in Escherichia coli. Trends Microbiol. 2005:13(5):236-42.

19. Vercruysse M, Fauvart M, Jans A, Beullens S, Braeken K, Cloots L, Engelen K, Marchal K, Michiels J. Stress response regulators identified through genomewide transcriptome analysis of the ( $\mathrm{p}) \mathrm{ppGpp}$ dependent response in Rhizobium etli. Genome Biol. 2011:12:R17.

20. Xiao H, Kalman M, Ikehara K, Zemel S, Glaser G, Cashel M. Residual guanosine 3',5'-bispyrophosphate synthetic activity of relA null mutants can be eliminated by spoT null mutations. J Biol Chem. 1991;266(9):5980-90.

21. Magnusson LU, Gummesson B, Joksimovic P, Farewell A, Nystrom T. Identical, independent, and opposing roles of ppGpp and DksA in Escherichia coli. J Bacteriol. 2007;189(14):5193-202.

22. Srivatsan A, Wang JD. Control of bacterial transcription, translation and replication by (p)ppGpp. Curr Opin Microbiol. 2008;11(2):100-5.

23. Barker MM, Gaal T, Gourse RL. Mechanism of regulation of transcription initiation by ppGpp. II. Models for positive control based on properties of RNAP mutants and competition for RNAP. J Mol Biol. 2001;305(4):689-702.

24. Potrykus K, Cashel M. (p)ppGpp: still magical? Annu Rev Microbiol. 2008;62: $35-51$.

25. Ross W, Vrentas CE, Sanchez-Vazquez P, Gaal T, Gourse RL. The magic spot: a ppGpp binding site on $E$. coli RNA polymerase responsible for regulation of transcription initiation. Mol Cell. 2013;50(3):420-9.

26. Chatnaparat T, Li Z, Korban SS, Zhao YF. The stringent response mediated by (p) ppGpp is required for virulence of Pseudomonas syringae pv. tomato and its survival on tomato. Mol Plant-Microbe Interact. 2015;28(7):776-89.

27. Chatnaparat T, Li Z, Korban SS, Zhao YF. The bacterial alarmone (p) ppGpp is required for virulence and controls cell size and survival of Pseudomonas syringae on plants. Environ Microbiol. 2015;17(11):4253-70.

28. Bleves S, Viarre V, Salacha R, Michel GP, Filloux A, Voulhoux R. Protein secretion systems in Pseudomonas aeruginosa: a wealth of pathogenic weapons. Int J Med Microbiol. 2010;300(8):534-43.

29. Economou A, Christie PJ, Fernandez RC, Palmer T, Plano GV, Pugsley AP. Secretion by numbers: protein traffic in prokaryotes. Mol Microbiol. 2006; 62(2):308-19.

30. Sarris PF, Skandalis N, Kokkinidis M, Panopoulos NJ. In silico analysis reveals multiple putative type $\mathrm{VI}$ secretion systems and effector proteins in Pseudomonas syringae pathovars. Mol Plant Pathol. 2010;11(6):795-804.

31. Cambronne ED, Roy CR. Recognition and delivery of effector proteins into eukaryotic cells by bacterial secretion systems. Traffic. 2006;7(8):929-39.

32. Hood RD, Singh P, Hsu F, Guvener T, Carl MA, et al. A type VI secretion system of Pseudomonas aeruginosa targets a toxin to bacteria. Cell Host Microbe. 2010;7(1):25-37.

33. Lindeberg M, Stavrinides J, Chang JH, Alfano JR, Collmer A, et al. Proposed guidelines for a unified nomenclature and phylogenetic analysis of type III hop effector proteins in the plant pathogen Pseudomonas syringae. Mol Plant-Microbe Interact. 2005;18(4):275-82.

34. Schechter LM, Roberts KA, Jamir YJ, Alfano R, Collmer A. Pseudomonas syringae type III secretion system targeting signals and novel effectors studied with a Cya translocation reporter. J Bacteriol. 2004;186(2):543-55.

35. Jovanovic M, James EH, Burrows PC, Rego FG, Buck M, Schumacher J.

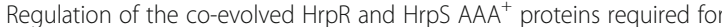
Pseudomonas syringae pathogenicity. Nat Commun. 2011;2:177.

36. Bernal $P$, Llamas MA, Filloux A. Type VI secretion systems in plant-associated bacteria. Environ Microbiol. 2018;20(1):1-15.

37. Haapalainen M, Mosorin H, Dorati F, Wu RF, Roine R, et al. Hcp2, a secreted protein of the phytopathogen Pseudomonas syringae pv. tomato DC3000, is 
required for fitness for competition against bacteria and yeasts. J Bacteriol. 2012;194(18):4810-22.

38. Moscoso JA, Mikkelsen H, Heeb S, Williams P, Filloux A. The Pseudomonas aeruginosa sensor RetS switches type III and type VI secretion via c-di-GMP signalling. Environ Microbiol. 2011;13(12):3128-38.

39. Bernard CS, Brunet YR, Gavioli ML, Loubes R, Cascales E. Regulation of type $\mathrm{VI}$ secretion gene clusters by $\delta^{54}$ and cognate enhancer binding proteins. J Bacteriol. 2011;193(9):2158-67.

40. Fenchel T. Microbial behavior in a heterogeneous world. Science. 2002; 296(5570):1068-71.

41. Hossain MM, Shibata S, Aizawa S-I, Tsuyumu S. Motility is an important determinant for pathogenesis of Erwinia carotovora subsp. carotovora. Physiol Mol Plant Pathol. 2005;66(4):134-43.

42. Taguchi F, Yamamoto M, Ohnishi-Kameyama M, Iwaki M, Yoshida M, Ishii T, Konishi T, Ichinose Y. Defects in flagellin glycosylation affect the virulence of Pseudomonas syringae pv.tabaci 6605. Microbiol. 2010; 156(1):72-80.

43. Potrykus K, Murphy H, Philippe N, Cashel M. ppGpp is the major source of growth rate control in E. coli. Environ Microbiol. 2011;13(3):563-75.

44. Ayala JA, Garrido T, De Pedro MA, Vicente M. Molecular biology of bacterial septation. In: Ghuysen JM, Hakenbeck R, editors. Bacterial Cell Wall. Netherland: Amsterdam: Elsevier; 1994. p. 73-101.

45. De Boer PAJ. Advances in understanding E. coli cell fission. Curr Opin Microbiol. 2010;13(6):730-7

46. Chien AC, Hill NS, Levin PA. Cell size control in bacteria. Curr Biol. 2012;22(9): R340-9.

47. Bi E, Lutkenhaus J. Interaction between the min locus and ftsZ. J Bacteriol, 1990;172(10):5610-6.

48. Haeusser DP, Garza AC, Buscher AZ, Levin PA. The division inhibitor EzrA contains a seven-residue patch required for maintaining the dynamic nature of the medial FtsZ ring. J Bacteriol. 2007;189(24):9001-10.

49. Lutkenhaus J. Assembly dynamics of the bacterial MinCDE system and spatial regulation of the $Z$ ring. Annu Rev Biochem. 2007;76:539-62.

50. Bi E, Lutkenhaus J. Analysis of fts Z mutations that confer resistance to the cell division inhibitor SulA. J Bacteriol. 1990;172(10):5602-9.

51. Bi E, Lutkenhaus J. Cell division inhibitors SulA and MinCD prevent formation of the FtsZ ring. J Bacteriol. 1993;175(4):1118-25.

52. Hu Z, Lutkenhaus J. Topological regulation of cell division in Escherichia coli involves rapid pole to pole oscillation of the division inhibitor MinC under the control of MinD and MinE. Mol Microbiol. 1999;34(1):82-90.

53. Fett WF, Osman SF, Fishman ML, Siebles TS III. Alginate production by plantpathogenic pseudomonads. Appl Environ Microbiol. 1986;52(3):466-73.

54. Lindow SE. Determinants of epiphytic fitness in bacteria. In: Andres JH, Hirano SS, editors. Microbial ecology of leaves. New York: SpringerVerlag; 1991. p. 295-314.

55. Kasapis S, Morris ER, Gross M, Rudolph K. Solution properties of Levan polysaccharide from Pseudomonas syringae pv. phaseolicola, and its possible role as a blocker of recognition during pathogenesis. Carbohydr Polym. 1994;23(1):55-64.

56. Penaloza-Vazquez A, Fakhr MK, Bailey AM, Bender CL. AlgR functions in algC expression and virulence in Pseudomonas syringae pv. syringae. Microbiol. 2004;150(8):2727-37.

57. Ramsey DM, Wozniak DJ. Understanding the control of Pseudomonas aeruginosa alginate synthesis and the prospects for management of chronic infections in cystic fibrosis. Mol Microbiol. 2005;56(2):309-22.

58. Yu J, Peñaloza-Vázquez A, Chakrabarty AM, Bender CL. Involvement of the EPS alginate in the virulence and epiphytic fitness of Pseudomonas syringae pv. syringae. Mol Microbiol. 1999;33(4):712-20.

59. Voloshin ON, Vanevski F, Khil PP, Camerini-Otero RD. Characterization of the DNA damage-inducible helicase DinG from Escherichia coli. J Biol Chem. 2003;278(30):28284-93

60. Cheng Z, Caillet A, Ren B, Ding H. Stimulation of Escherichia coli DNA damage inducible DNA helicase DinG by the single-stranded DNA binding protein SSB. FEBS Lett. 2012;586(21):3825-30.

61. Boubakri H, de Septenville AL, Viguera E, Michel B. The helicases DinG, rep and UvrD cooperate to promote replication across transcription units in vivo. EMBO J. 2010;29(1):145-57.

62. Acharya N, Varshney U. Biochemical properties of single-stranded DNAbinding protein from Mycobacterium smegmatis, a fast-growing mycobacterium and its physical and functional interaction with uracil DNA glycosylases. J Mol Biol. 2002;318(5):1251-64.
63. Butland G, Peregrin-Alvarez JM, Li J, Yang WH, Yang XC, et al. Interaction network containing conserved and essential protein complexes in Escherichia coli. Nature. 2005;433:531-7.

64. Scheuermann R, Tam S, Burgers PMJ, Lu C, Echols H. Identification of the esubunit of Escherichia coli DNA polymerase III holoenzyme as the dnaQ gene product: a fidelity subunit for DNA replication. Proc Natl Acad Sci U S A. 1983;80(23):7085-9.

65. Kanaya S, Katsuda-Nakai C, Ikebara M. Importance of the positive charge cluster in Escherichia coli ribonuclease $\mathrm{HI}$ for the effective binding of the substrate. J Biol Chem. 1991;266(18):11621-7.

66. Brill SJ, DiNardo S, Voelkel-Meiman K, Sternglanz R. Need for DNA topoisomerase activity as a swivel tor DNA replication and for transcription of ribosomal RNA. Nature. 1987;326:414-6.

67. Charollais J, Dreyfus M, lost I. CsdA, a cold-shock RNA helicase from Escherichia coli, is involved in the biogenesis of $50 \mathrm{~S}$ ribosomal subunit. Nucleic Acids Res. 2004;32(9):2751-9.

68. Tanner NK, Linder P. DExD/H box RNA helicases: from generic motors to specific dissociation functions. Mol Cell. 2001;8(2):251-62.

69. Iost I, Dreyfus M. DEAD-box RNA helicases in Escherichia coli. Nucleic Acids Res. 2006;34(15):4189-97.

70. Charollais J, Pflieger D, Vinh J, Dreyfus M, lost I. The DEAD-boxRNA helicase $\mathrm{SrmB}$ is involved in the assembly of $50 \mathrm{~S}$ ribosomal subunits in Escherichia coli. Mol Microbiol. 2003;48(5):1253-65.

71. Lempiainen H, Shore D. Growth control and ribosome biogenesis. Curr Opin Cell Biol. 2009;21(6):855-63.

72. Li GW, Burkhardt D, Gross C, Weissman JS. Quantifying absolute protein synthesis rates reveals principles underlying allocation of cellular resources. Cell. 2014;157(3):624-35.

73. Jorgensen $P$, Tyers $M$, Warner JR. Forging the factory: ribosome synthesis and growth control in budding yeast. In: Hall MN, Raff M, Thomas G, editors Cell Growth: Control of Cell Size. Cold Spring Harbor: Laboratory Press; 2004. p. 329-70.

74. Berens RL, Krug EC, Marr JJ. Purine and pyrimidine metabolism. In: Marr JJ, Muller $\mathrm{M}$, editors. Biochemistry and molecular biology of parasites. London: Academic; 1995. p. 89-117.

75. An S, Kumar R, Sheets ED, Benkovic SJ. Reversible compartmentalization of de novo purine biosynthetic complexes in living cells. Science. 2008; 320(5872):103-6.

76. Liechti G, Goldberg JB. Helicobacter pylori relies primarily on the purine salvage pathway for purine nucleotide biosynthesis. J Bacteriol. 2012;194(4): 839-54.

77. Brune M, Schumann R, Wittinghofer F. Cloning and sequencing of the adenylate kinase gene (adk) of Escherichia coli. Nucleic Acids Res. 1985; 13(19):7139-51.

78. Willemoes M, Kilstrup M. Nucleoside triphosphate synthesis catalysed by adenylate kinase is ADP dependent. Arch Biochem Biophys. 2005;444(2): 195-9.

79. Kilstrup M, Hammer K, Ruhdal Jensen P, Martinussen J. Nucleotide metabolism and its control in lactic acid bacteria. FEMS Microbiol Rev. 2005; 29(3):555-90.

80. Switzer RL, Zalkin H, Saxild HH. Purine, pyrimidine, and pyridine nucleotide metabolism. In: Sonenshein AL, Hoch JA, Losick R, editors. Bacillus subtilis and its relatives: from genes to cells. Washington: ASM Press; 2002. p. 255-69.

81. Zhu K, Choi KH, Schweizer HP, Rock CO, Zhang YM. Two aerobic pathways for the formation of unsaturated fatty acids in Pseudomonas aeruginosa. Mol Microbiol. 2006;60(2):260-73.

82. Ghisla S, Thorpe C. Acyl-CoA dehydrogenases. A mechanistic overview. Eur J Biochem. 2004;271:494-508.

83. Davis MS, Solbiati J, Cronan JE Jr. Overproduction of acetyl-CoA carboxylase activity increases the rate of fatty acid biosynthesis in Escherichia coli. J Biol Chem. 2000;275(37):28593-8.

84. Yan JF, Cheng RB, Lin XZ, You S, Li K, Rong H, Ma Y. Overexpression of acetyl-CoA synthetase increased the biomass and fatty acid proportion in microalga Schizochytrium. Appl Microbiol Biotechnol. 2013;97(5):1933-9.

85. Kutchma AJ, Hoang TT, Schweizer HP. Characterization of a Pseudomonas aeruginosa fatty acid biosynthetic gene cluster: purification of acyl carrier protein (ACP) and malonyl-coenzyme a:ACP transacylase (FabD). J Bacteriol. 1999:181(17):5498-504.

86. Shen Z, Byers DM. Isolation of Vibrio harveyi acyl carrier protein and the fabG, acpP, and fabF genes involved in fatty acid biosynthesis. J Bacteriol. 1996;178(2):571-3. 
87. Mansilla MC, Cybulski LE, Albanesi D, de Mendoza D. Control of membrane lipid fluidity by molecular thermosensors. J Bacteriol. 2004; 186(20):6681-8

88. Heird WC, Lapillonne A. The role of essential fatty acids in development. Annu Rev Nutr. 2005;25:549-71.

89. Mansilla MC, De Mendoza D. The Bacillus subtilis desaturase: a model to understand phospholipid modfication and temperature sensing. Arch Microbiol. 2005;183(4):229-35.

90. Traxler MF, Summers SM, Nguyen HT, Zacharia VM, Hightower GA, Smith JT, Conway T. The global, ppGpp-mediated stringent response to amino acid starvation in Escherichia coli. Mol Microbiol. 2008;68(5):1128-48.

91. Richter M. Functional diversity of organic molecule enzyme cofactors. Nat Prod Rep. 2013:30(10):1324-45

92. Abbas CA, Sibirny AA. Genetic control of biosynthesis and transport of riboflavin and flavin nucleotides and construction of robust biotechnological producers. Microbiol Mol Biol Rev. 2011;75(2):321-60

93. Haase I, Gräwert T, Illarionov B, Bacher A, Fischer M. Recent advances in riboflavin biosynthesis. Methods Mol Biol. 2014;1146:15-40.

94. Illarionov B, Kemter K, Eberhardt S, Richter G, Cushman M, Bacher A. Riboflavin synthase of Escherichia coli effect of single amino acid substitutions on reaction rate and ligand binding properties. J Biol Chem. 2001;276(15):11524-30.

95. Zhang JL, Kang Z, Chen J, Du GC. Optimization of the heme biosynthesis pathway for the production of 5-aminolevulinic acid in Escherichia coli. Sci Rep. 2015;5:8584

96. Dailey HA, Gerdes S, Dailey TA, Burch JS, Phillips JD. Noncanonical coproporphyrin-dependent bacterial heme biosynthesis pathway that does not use protoporphyrin. Proc Natl Acad Sci U S A. 2015;112(7):2210-5.

97. Saha BC. Purification and characterization of a novel mannitol dehydrogenase from Lactobacillus intermedius. Biotechnol Prog. 2004;20(2): 537-42.

98. Khankal R, Chin J, Cirino P. Role of xylose transporters in xylitol production from engineered Escherichia coli. J Biotechnol. 2008;134:246-52.

99. Dauvillée D, Kinderf IS, Li Z, Kosar-Hashemi B, Samuel MS, Rampling L, Ball S, Morell MK. Role of the Escherichia coli glgX gene in glycogen metabolism. J Bacteriol. 2005;187(4):1465-73.

100. Martinez-Antonio A, Collado-Vides J. Identifying global regulators in transcriptional regulatory networks in bacteria. Curr Opin Microbiol. 2003; 6(5):482-9.

101. Schultz JE, Matin A. Molecular and functional characterization of a carbon starvation gene of Escherichia coli. J Mol Biol. 1991;218(1):129-40.

102. Dubey AK, Baker CS, Suzuki K, Jones AD, Pandit P, Romeo T, Babitzke P. CsrA regulates trans-lation of the Escherichia coli carbon starvation gene, cstA,by blocking ribosome access to the cstA transcript. J Bacteriol. 2003;|185(15): 4450-60.

103. Durfee T, Hansen AM, Zhi H, Blattner FR, Jin DJ. Transcription profiling of the stringent response in Escherichia coli. J Bacteriol. 2008;190(3): 1084-96.

104. Schulte JE, Goulian M. The phosphohistidine phosphatase SixA targets a phosphotransferase system. mBio. 2018;9(6):e01666-18.

105. Elizabeth SV, Bender CL. The phytotoxin coronatine from Pseudomonas syringae pv. tomato DC3000 functions as a virulence factor and influences defense pathways in edible brassicas. Mol Plant Pathol. 2007; 8(1):83-92.

106. Lu SE, Scholz-Schroeder BK, Gross DC. Characterization of the salA, syrF, and syrG regulatory genes located at the right border of the syringomycin gene cluster of Pseudomonas syringae pv. syringae. Mol Plant-Microbe Interact. 2002;15(1):43-53.

107. Ge YX, Lee JH, Liu J, Yang HW, Tian YL, Hu BS, Zhao YF. Homologues of the RNA binding protein RsmA in Pseudomonas syringae pv. tomato DC3000 exhibit distinct binding affinities with non-coding small RNAs and have distinct roles in virulence. Mol Plant Pathol. 2019:20(9):1217-36.

108. Buell CR, Joardar V, Lindeberg M, Selengut J, Paulsen IT, et al. The complete genome sequence of the Arabidopsis and tomato pathogen Pseudomonas syringae pv. tomato DC3000. Proc Natl Acad Sci U S A. 2003;100(18):10181-6.

109. Langmead B, Trapnell C, Pop M, Salzberg SL. Ultrafast and memory efficient alignment of short DNA sequences to the human genome. Genome Biol. 2009;10(3):R25.

110. McCarthy DJ, Chen Y, Smyth GK. Differential expression analysis of multifactor RNA-seq experiments with respect to biological variation. Nucleic Acids Res. 2012;40(10):4288-97.
111. Robinson MD, McCarthy DJ, Smyth GK. edgeR: a bioconductor package for differential expression analysis of digital gene expression data. Bioinformatics. 2010;26(1):139-40.

112. Champion OL, Gourlay LJ, Scott AE, Lassaux P, Conejero L, Perletti L, Hemsley C, Prior J, Bancroft G, Bolognesi M. Immunisation with proteins expressed during chronic murine melioidosis provides enhanced protection against disease. Vaccine. 2016;34(14):1665-71.

\section{Publisher's Note}

Springer Nature remains neutral with regard to jurisdictional claims in published maps and institutional affiliations.

\section{Ready to submit your research? Choose BMC and benefit from:}

- fast, convenient online submission

- thorough peer review by experienced researchers in your field

- rapid publication on acceptance

- support for research data, including large and complex data types

- gold Open Access which fosters wider collaboration and increased citations

- maximum visibility for your research: over $100 \mathrm{M}$ website views per year

At $\mathrm{BMC}$, research is always in progress.

Learn more biomedcentral.com/submissions 